\title{
A Site of Auditory Experience-Dependent Plasticity in the Neural Representation of Auditory Space in the Barn Owl's Inferior Colliculus
}

\author{
Joshua I. Gold and Eric I. Knudsen \\ Department of Neurobiology, Stanford University, Stanford, California 94305-5125
}

The barn owl's optic tectum contains a map of auditory space that is based, in part, on a map of interaural time difference (ITD). Previous studies have shown that this ITD map is shaped by auditory experience. In this study, we investigated whether the plasticity responsible for experience-induced changes in ITD tuning in the tectum occurs within the tectum itself or at an earlier stage in the auditory pathway.

We altered auditory experience in young owls by implanting an acoustic filtering device in one ear that caused frequencydependent changes in sound timing and level. We analyzed the representation of ITD in normal and device-reared owls in two nuclei in the ascending pathway: the external nucleus of the inferior colliculus (ICX), the primary source of ascending auditory input to the tectum, and the lateral shell of the central

The barn owl's optic tectum and its mammalian homolog, the superior colliculus, contain maps of both visual and auditory space (Gordon, 1973; Updyke, 1974; Harris et al., 1980; Knudsen, 1982; King and Palmer, 1983; Middlebrooks and Knudsen, 1984). Unlike the visual map, which arises from topographic projections from the retina, the auditory map is derived in a series of stages from information about the timing, level, and spectra of sounds that arrive at the two ears. This derivation is complicated by the fact that the values of these cues depend not only on the location of a sound source, but on the physical characteristics of the listener and the frequency content of the sound, as well. To help account for variability in the values of these cues, the response properties of tectal neurons tuned to auditory space are calibrated by experience (Knudsen, 1983a, 1985; King et al., 1988, 1994; Knudsen and Brainard, 1991; Gold and Knudsen, 1999). In the present study, we investigated whether changes in tectal unit response properties that result from auditory experience reflect plasticity intrinsic to the tectum itself or plasticity that occurs at an earlier site in the ascending auditory pathway.

Previous studies have demonstrated that adjustments in binaural response properties that result from different sensory manipulations can occur in the ascending pathway before the level of the optic tectum. For example, raising owls with a chronic monaural occlusion causes changes in the representation of interaural

\footnotetext{
Received Jan. 4, 2000; revised Feb. 17, 2000; accepted Feb. 18, 2000.

This work was supported by the National Institute on Deafness and Other Communication Disorders, National Institutes of Health Grant R01 DC00155-18. We thank Michael Shadlen for helpful comments on this manuscript and Phyllis Knudsen for expert technical assistance.

Correspondence should be addressed to Dr. Joshua I. Gold, Department of Physiology and Biophysics, University of Washington Medical School, Box 357290, Seattle, WA 98195-7290. E-mail: jig@u.washington.edu.

Copyright (C) 2000 Society for Neuroscience $0270-6474 / 00 / 203469-18 \$ 15.00 / 0$
}

nucleus of the inferior colliculus (ICCls), the primary source of input to the ICX. In the ICX, device rearing caused adaptive, frequency-dependent changes in ITD tuning, as well as changes in frequency tuning. These changes in tuning were similar to changes that occurred in the optic tectum in the same owls. In contrast, in the ICCls, tuning for ITD and frequency was unaffected by device rearing. The data indicate that plasticity at the level of the ICX is largely responsible for the adaptive adjustments in ITD tuning and frequency tuning that are observed in the optic tecta of owls raised with abnormal auditory experience.

Key words: Tyto alba; sound localization; hearing impairment; development; sensory experience; superior colliculus; inferior colliculus

level difference (ILD) in the posterior division of the ventral nucleus of the lateral lemniscus, the first site of interaural level comparison in the owl's brainstem (Mogdans and Knudsen, 1994). These changes are smaller in magnitude but are in the same direction as those that occur in the optic tecta of the same owls (Mogdans and Knudsen, 1992). Moreover, raising owls with prismatic spectacles that optically shift the visual field results in a systematic shift in the tuning of units for interaural time difference (ITD) in the external nucleus of the inferior colliculus (ICX); a matching shift is observed in the tectum, which receives direct, ascending input from the ICX (Brainard and Knudsen, 1993).

In this study, we caused frequency-dependent changes in the auditory localization cues experienced by young owls by raising them with an acoustic filtering device in one ear. This manipulation induces adaptive, frequency-dependent changes in the auditory spatial tuning of tectal neurons that reflect, in part, changes in their tuning for ITD and frequency (Gold and Knudsen, 1999, 2000). We analyzed the effects of device rearing on the representations of ITD and frequency in the two nuclei immediately preceding the tectum in the ascending auditory pathway, the ICX and the lateral shell of the central nucleus of the inferior colliculus (ICCls) (Fig. 1). The results indicate that, like prism rearing, device rearing has little effect on the functional organization of the ICCls but causes dramatic changes in the ICX. This deviceinduced plasticity can largely account for the changes in both ITD and frequency tuning that are observed in the optic tectum.

\section{MATERIALS AND METHODS}

Eight barn owls (Tyto alba) raised with an acoustic filtering device in the right ear and five normal owls were used in this study. All of the owls were used in previous studies (Gold and Knudsen, 1999, 2000). The owls were provided for in accordance with the National Institutes of Health 
A
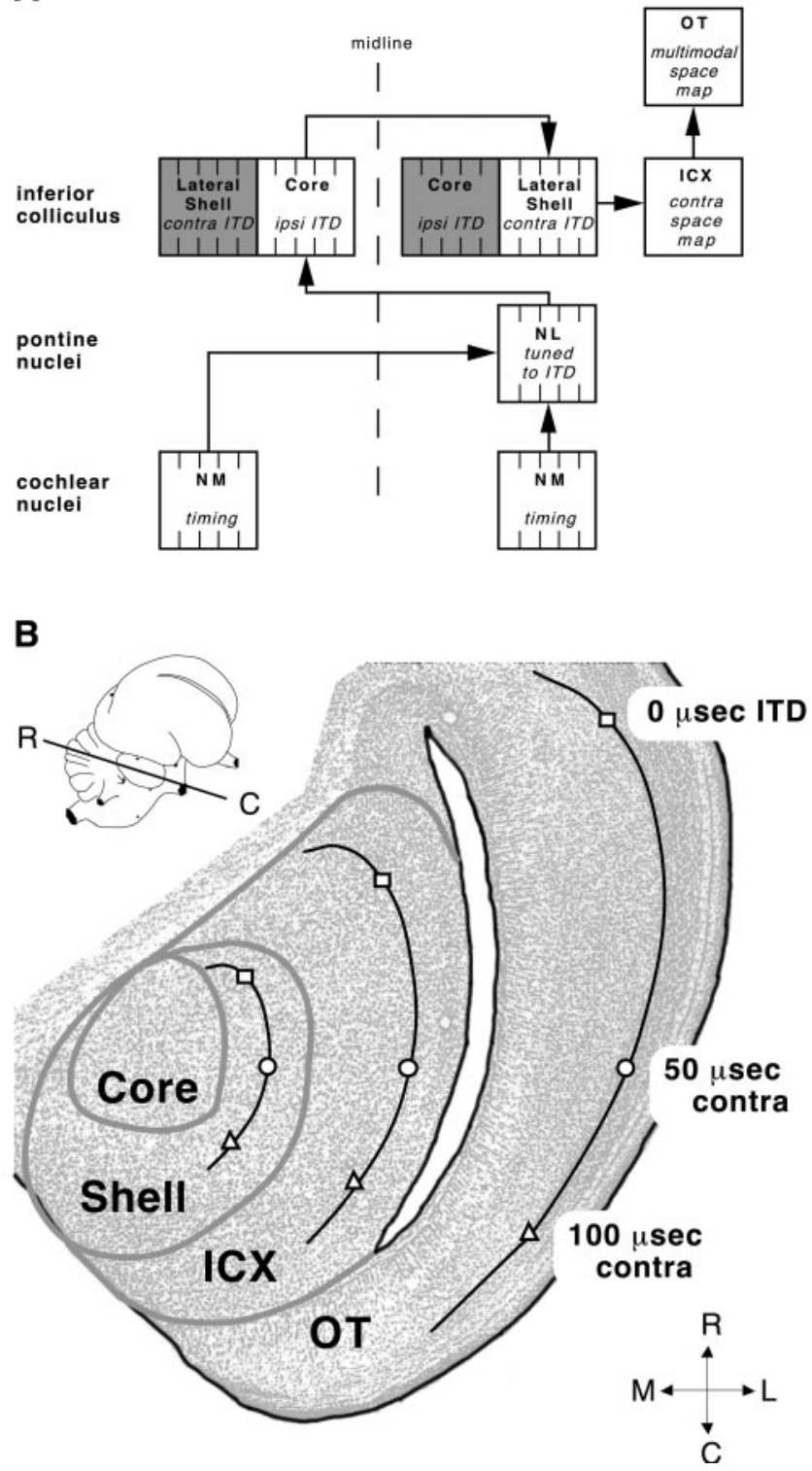

Figure 1. The ascending ITD pathway leading to the optic tectum $(O T)$ (adapted from Brainard and Knudsen, 1993). A, Block diagram of the principal nuclei involved in the processing of timing information. All nuclei are bilaterally symmetrical. Vertical tick marks indicate tonotopic organization. Frequency-specific timing information is conveyed from each nucleus magnocellularis $(N M)$ to the nucleus laminaris $(N L)$, the first site of interaural phase comparison (Sullivan and Konishi, 1986; Carr and Konishi, 1988, 1990). The NL projects contralaterally to the core subdivision of the central nucleus of the inferior colliculus (Takahashi and Konishi, 1988), which projects, in turn, to the contralateral ICC lateral shell (Takahashi et al., 1989). Within the ICC core and ICCls, individual neurons are tuned for IPD, and given dorsoventral array of neurons represents a single ITD value across the range of best frequencies (Wagner et al., 1987). Timing information from the ICCls converges across frequency channels in the external nucleus of the inferior colliculus $(I C X)$, where neurons are organized with respect to their binaural tuning properties to form a physiological map of auditory space (Knudsen, 1983b; Wagner et al., 1987). The ICX space map is conveyed via point-to-point projections to the optic tectum (Knudsen and Knudsen, 1983). B, Schematic diagram of a horizontal section cut parallel to the long axis of the optic tectum (see inset), illustrating the representation of ITD in the optic tectum, ICX, and ICCls. Best ITD varies systematically along the rostrocaudal axis of each nucleus, such that ITD values normally produced by sound sources located in frontal space (near $0 \mu \mathrm{sec}$ ) are represented rostrally,
Guide for the Care and Use of Laboratory Animals and the guidelines of the Stanford University Institutional Animal Care and Use Committee. Auditory manipulation. An acoustic filtering device placed chronically in one ear canal was used to alter auditory experience. The device was a custom-designed chamber made from acetal delrin (Plastics SRT) that was sutured into the right ear canal and rested just behind the preaural flap and in front of the facial ruff feathers (the owl's ear canals are asymmetrically positioned on its head, and the left ear canal opens at an angle relative to the facial ruff feathers that makes it difficult to place the device on the left side). A more detailed description of the device, including cochlear microphonic measurements of its frequency-specific effects on sound timing and level, can be found in Gold and Knudsen (1999).

Owls raised with the device were first binaurally occluded with dense foam rubber earplugs (E.A.R. Cabot Corporation) from $25-35 \mathrm{~d}$ of age to limit auditory experience while their ear canals were open but not yet large enough to accommodate the acoustic device. At the end of this period, the binaural foam plugs were removed, and the acoustic device was sutured into the right ear canal. The owls were anesthetized with halothane $(1 \%)$ in a mixture of oxygen and nitrous oxide $(5: 4)$ while the earplugs and the acoustic device were sutured in place.

All owls were initially raised in brooding boxes with their siblings. After the device was inserted, each owl was placed in an individual cage located next to a large flight cage that housed many adult owls, providing a rich visual and auditory environment. When the owl could fly, at $\sim 60$ $\mathrm{d}$ of age, it was placed in the large flight cage.

Electrophysiology. Each owl was prepared for electrophysiological measurements in a single surgical session during which it was anesthetized with halothane and nitrous oxide. A small, stainless steel plate was cemented to the base of the skull for securing the head in a stereotaxic apparatus, and small craniotomies were made above the optic tectum and inferior colliculus (IC) on each side of the brain. The craniotomies were covered with dental acrylic, which was removed and replaced for each recording session. At the end of the procedure, the tissues surrounding all incisions were infused with lidocaine, treated with betadine, and sutured back together.

At the beginning of each recording session, the owl was anesthetized with halothane and nitrous oxide, wrapped in a soft leather jacket, and given an intramuscular injection of $3 \mathrm{ml}$ of $2.5 \%$ dextrose in $0.45 \%$ sterile saline. The acoustic device was removed, and the ear canal and eardrum were inspected for damage and cleaned of earwax. The owl was suspended in a prone position in a stereotaxic apparatus in a soundattenuating chamber (Industrial Acoustics Company, model 404A) lined with acoustic foam to suppress echoes, and its head was positioned using retinal landmarks (the barn owl's eyes are essentially fixed in its head).

Except during the $\sim 20$ min of set-up, the owl was unanesthetized and typically remained calm and motionless during the course of the experiment. Occasionally, however, the owl became active, at which time recording was suspended while a brief dose of halothane and nitrous oxide or nitrous oxide alone was administered.

Electrophysiological measurements were made extracellularly using tungsten microelectrodes that were stereotaxically positioned and advanced with a mechanical microdrive. A level discriminator was used to isolate action potentials generated by one neuron or a small group of neurons at each recording site, and a computer stored the times of these action potentials relative to stimulus onset time.

At the end of each recording session, the craniotomy was bathed in chloramphenicol $(0.5 \%)$ and resealed with dental acrylic, and the device was sutured back into place. The owl was kept warm with a heat lamp until it had fully recovered (usually $1-2 \mathrm{hr}$ ) and then was returned to its home flight cage.

Auditory measurements. Computer-generated stimuli were presented through a pair of matched Knowles subminiature earphones (ED-1914) coupled to damping assemblies (BF-1743). The earphones were placed in the ear canals $\sim 5 \mathrm{~mm}$ from the tympanic membranes with the device removed. The amplitude and phase spectra of the earphones were equalized to within $\pm 2 \mathrm{~dB}$ and $\pm 2 \mu \mathrm{sec}$, respectively, from 1 to $12 \mathrm{kHz}$ by computer adjustments of the stimulus waveforms. Sound levels were

\section{$\leftarrow$}

whereas increasingly contralateral-ear-leading values are represented more caudally (Moiseff and Konishi, 1981a; Wagner et al., 1987; Olsen et al., 1989). In the ICCcore, $0 \mu \mathrm{sec}$ ITD is represented rostrally and increasingly ipsilateral-ear-leading values are represented more caudally. 
calibrated using A-weighted signals from a Bruel and Kjær half-inch condenser microphone positioned $1 \mathrm{~cm}$ from the earphone. Bursts of broadband noise had rise/fall times of $0 \mathrm{msec}$ and a passband of 3-12 $\mathrm{kHz}$, the lower bound set to minimize propagation through the interaural canal (Moiseff and Konishi, 1981b). Bursts of narrowband noise (50 msec duration) were generated with a $1 \mathrm{kHz}$-wide digital filter centered on the given frequency; these and pure tone bursts had linear rise/fall times of $5 \mathrm{msec}$.

The response to a sound presentation was defined as the number of spikes counted in the 100 msec immediately after stimulus onset (poststimulus response) minus the number of spikes counted in the $100 \mathrm{msec}$ immediately preceding stimulus onset (baseline activity). Response threshold was defined as the lowest average binaural level at which the response to a given stimulus was at least $25 \%$ of the maximum response evoked at any level up to $70 \mathrm{~dB}$ sound pressure level. ITD, ILD, and frequency tuning curves were generated by presenting stimuli $0.7-1.0 \mathrm{sec}$ apart at 20-30 dB above threshold and collecting responses over 10-20 repetitions. For each tuning curve, the width of the maximum response peak was defined as the uninterrupted range over which responses were $>50 \%$ of the maximum response. The midpoint of that range was defined as the best value for the peak. For ITD tuning curves with multiple peaks, the best value was taken from the peak nearest to $0 \mu \mathrm{sec}$ ITD or, in the ICC, from the peak that was common to all units in a dorsoventral penetration, the array-specific ITD (Wagner et al., 1987).

ITD tuning was measured by varying the interaural delay in 10-20 $\mu \mathrm{sec}$ intervals over a $100-300 \mu \mathrm{sec}$ range of values between -250 and $250 \mu \mathrm{sec}$; positive and negative values indicate right- and left-ear-leading ITDs, respectively. Stimuli were presented using the best ILD for the given stimulus, which was measured by varying the ILD in $2-4 \mathrm{~dB}$ intervals over a $15-40 \mathrm{~dB}$ range of values between -30 and $30 \mathrm{~dB}$ at a fixed average binaural level.

Frequency-response functions were measured using both tonal and narrowband ( $1 \mathrm{kHz}$ bandwidth) stimuli. Tonal stimuli were presented using the broadband best ITD and best ILD for that site and at 20-30 dB above the threshold measured for the lowest frequency $(>3 \mathrm{kHz})$ that elicited a response. Stimuli with a bandwidth of $1 \mathrm{kHz}$ were presented using the best ITD and best ILD and at $20-30 \mathrm{~dB}$ above the threshold for the given stimulus.

The frequency dependence of ITD tuning was assessed in the optic tectum, ICX, and ICCls. In the optic tectum and the ICX, neurons are broadly tuned for frequency (Knudsen and Konishi, 1978; Knudsen, 1984a; Olsen et al., 1989; Brainard and Knudsen, 1993). Therefore, ITD tuning in those nuclei was measured using narrowband $(1 \mathrm{kHz}$ bandwidth) stimuli with different center frequencies, and the frequency dependence was quantified as (1) the range of narrowband best ITDs measured for all stimulus frequencies that yielded ITD tuning and (2) the difference between narrowband best ITDs measured using stimulus center frequencies between 3.5 and $4.5 \mathrm{kHz}$ and those measured using higher frequencies, up to $9 \mathrm{kHz}$ (a positive or negative value indicates that the higher frequency best ITD was more right- or left-ear leading, respectively, than the $\sim 4 \mathrm{kHz}$ best ITD). In contrast, neurons in the ICCls are narrowly tuned for frequency (Knudsen, 1984b; Wagner et al., 1987); thus, the ITD tuning measured at a given ICCls site was specific to the best frequency. In fact, at $14 \mathrm{ICCls}$ sites, the best ITD measured using a broadband stimulus was the same as the best ITD measured using a narrowband stimulus with a passband that matched the frequency tuning at that site (paired $t$ test, $p=0.56$ ). Consequently, the frequency dependence of ITD tuning in the ICCls was assessed by comparing broadband ITD tuning across sites along dorsoventral electrode penetrations that traversed a wide range of the frequency representation. For each electrode penetration, the frequency dependence of ITD tuning was quantified as (1) the range of best ITDs compared with the range of best frequencies measured and (2) the difference between the best ITDs measured at sites with best frequencies between 3 and $4.5 \mathrm{kHz}$ and those measured at sites with higher best frequencies (a positive or negative value indicates that the higher frequency best ITD was more right- or left-ear leading, respectively, than the $\sim 4 \mathrm{kHz}$ best ITD).

Frequency-specific representations of ITD were analyzed in the optic tectum, ICX, and ICCls. In the optic tectum, the representation of ITD was determined relative to visual receptive field (RF) locations (Olsen et al., 1989; Brainard and Knudsen, 1993; Gold and Knudsen, 2000). These were measured by projecting bars and spots of light onto a calibrated, translucent hemisphere placed directly in front of the owl, and their locations were quantified using a double-pole coordinate system in which the visual axes defined $0^{\circ}$ azimuth, $0^{\circ}$ elevation (Knudsen, 1982). In the
ICX and ICCls, the representations of ITD were determined based on the locations of recording sites reconstructed from electrolytic lesions (Brainard and Knudsen, 1993) (see Histology, below).

Targeting of nuclei. The optic tectum was targeted stereotaxically and was recognized by characteristic bursting activity and spatially restricted visual and auditory RFs (Knudsen, 1982). Electrode position within the optic tectum was determined on the basis of visual RF location. The ICCls and the ICX were targeted stereotaxically by positioning the electrode $2 \mathrm{~mm}$ medial, $3 \mathrm{~mm}$ caudal relative to the tectal representation of $0^{\circ}$ azimuth, $+10^{\circ}$ elevation. A number of criteria were used to distinguish between subdivisions of the IC, including stereotaxic position, response latency, and unit tuning to both frequency and ILD. The ICCls is located medial to the ICX, and neurons in the ICCls respond, on average, with a shorter latency than those in the ICX. Neurons in the ICC are sharply tuned for frequency, and best frequency systematically progresses from low to high with dorsoventral depth (along the trajectory of the electrode penetration) (Knudsen and Konishi, 1978; Wagner et al., 1987). In contrast, neurons in the ICX usually respond to a broad range of frequencies, and there is no systematic progression of best frequency with depth (Knudsen and Konishi, 1978). Many neurons in the ICCls are tuned for ILD, but there is no apparent organization according to ILD tuning (Brainard and Knudsen, 1993). Neurons in the ICX are tuned for ILD, and best ILDs change systematically with recording depth from right-ear greater dorsally to left-ear greater ventrally (Mogdans and Knudsen, 1993). As shown in Table 1, response latency, frequency tuning width, and progression of best ILD with dorsoventral electrode depth were unaffected by device rearing and differed significantly between the ICX and ICCls. We verified our classifications of recording sites based on these properties by reconstructing electrolytic lesions at 60 of the 653 sites tested.

Within the ICC, the lateral shell was distinguished from the core on the basis of stereotaxic position and unit tuning to ITD and ILD. Neurons in the ICCcore, which is located on the medial edge of the ICCls, typically respond to ipsilateral-ear-leading ITD values (neurons in the ICCls are tuned to contralateral-ear-leading values) and exhibit little or no sensitivity to ILD (Wagner et al., 1987).

Histology. After electrophysiological measurements were completed, the topography of ITD representation in the IC was mapped in a single recording session. Electrolytic lesions were made by passing 3-5 $\mu \mathrm{A}$ of cathodal current through the recording electrode for $15 \mathrm{sec}$. After 5-12 $\mathrm{d}$ of survival, the owls were given an overdose of sodium pentobarbital $(300 \mathrm{mg} / \mathrm{kg}$ ) and perfused through the heart with formalin. Frozen sections, $40 \mu \mathrm{m}$ thick, were cut in a horizontal plane parallel to the long axis of the optic tectum. Every third section was stained with cresyl violet to locate lesions, and alternate sections were stained with an antibody for calcium binding protein-like antigen (17E4F2, provided by C. E. Carr, Department of Zoology, University of Maryland) to mark the ICCcore (Takahashi et al., 1987). This material was used to correlate ITD tuning with recording site location in the IC.

\section{RESULTS}

Raising owls with an acoustic filtering device in one ear causes changes in ITD and frequency tuning in the optic tectum (Gold and Knudsen, 2000). These changes, like the acoustic effects of the device (Table 2), depend on frequency. We used this frequency dependence to guide our investigation of whether the changes in tectal unit tuning are intrinsic to the tectum or whether they occur at an earlier stage in the ascending auditory pathway. We characterized the effects of device rearing on the frequency dependence of ITD tuning, frequency-specific maps of ITD, and frequency-response properties in the optic tectum. We then looked for similar effects in the ICX and ICCls. Results from each nucleus are presented separately below.

\section{Optic tectum}

Neurons in most regions of the optic tectum are broadly tuned for frequency, typically responding to a $3-4 \mathrm{kHz}$ range of frequencies centered between 5.5 and $7.5 \mathrm{kHz}$ (Knudsen, 1984a; Olsen et al., 1989). Therefore, we assessed the frequency-dependent effects of device rearing on the ITD tuning of tectal units by measuring ITD tuning at individual sites using both a broadband $(3-12 \mathrm{kHz})$ 
Table 1. Response properties of neurons in the $\mathrm{IC}^{a}$

\begin{tabular}{|c|c|c|c|c|c|c|c|c|}
\hline Location & Experience & Lesion $^{b}$ & $\mathrm{np}^{c}$ & $\mathrm{~ns}^{d}$ & $\begin{array}{l}\text { Response } \\
\text { latencye }^{e} \\
(\mathrm{msec})\end{array}$ & $\begin{array}{l}\text { Frequency } \\
\text { tuning width } \\
(\mathrm{kHz})\end{array}$ & $\begin{array}{l}\text { Best frequency } \\
\text { progression }^{g} \\
(\mathrm{kHz} / \mathrm{mm})\end{array}$ & $\begin{array}{l}\text { Best ILD } \\
\text { progression }^{h} \\
(\mathrm{~dB} / \mathrm{mm})\end{array}$ \\
\hline \multirow[t]{4}{*}{ ICX } & \multirow[t]{2}{*}{ Normal } & Yes & 4 & 8 & $7.8 \pm 1.2$ & $2.5 \pm 0.6$ & $0.3 \pm 1.8$ & $-12.3 \pm 9.7$ \\
\hline & & No & 8 & 19 & $7.8 \pm 1.8$ & $2.9 \pm 0.7$ & $1.3 \pm 2.7$ & $-20.3 \pm 9.1$ \\
\hline & \multirow[t]{2}{*}{ Device-reared } & Yes & 16 & 25 & $8.9 \pm 2.8$ & $2.8 \pm 0.9$ & $3.3 \pm 2.8$ & $-10.0 \pm 20.3$ \\
\hline & & No & 22 & 43 & $8.7 \pm 4.3$ & $3.2 \pm 0.6$ & $6.4 \pm 4.2$ & $-16.7 \pm 19.3$ \\
\hline \multicolumn{2}{|c|}{ Combined data: } & & 50 & 95 & $8.5 \pm 3.5$ & $3.0 \pm 0.8$ & $3.2 \pm 3.8$ & $-16.3 \pm 16.4$ \\
\hline \multirow[t]{4}{*}{ ICCIs } & \multirow[t]{2}{*}{ Normal } & Yes & 5 & 12 & $5.8 \pm 1.4$ & $1.4 \pm 0.3$ & $5.9 \pm 3.2$ & $6.7 \pm 22.0$ \\
\hline & & No & 29 & 145 & $6.1 \pm 1.3$ & $1.5 \pm 0.6$ & $4.4 \pm 3.1$ & $4.9 \pm 36.9$ \\
\hline & \multirow[t]{2}{*}{ Device-reared } & Yes & 12 & 15 & $5.6 \pm 1.3$ & $1.4 \pm 0.3$ & $3.7 \pm 1.5$ & $-3.2 \pm 19.9$ \\
\hline & & No & 116 & 386 & $5.7 \pm 1.2$ & $1.3 \pm 0.4$ & $4.3 \pm 2.9$ & $2.5 \pm 26.2$ \\
\hline \multicolumn{2}{|c|}{ Combined data: } & & 162 & 558 & $5.8 \pm 1.2^{*}$ & $1.4 \pm 0.5^{*}$ & $4.3 \pm 2.9$ & $2.8 \pm 28.0^{*}$ \\
\hline
\end{tabular}

${ }^{a}$ Values are mean \pm SD.

${ }^{b}$ Whether or not the sites' locations were verified using reconstruction of electrolytic lesions.

${ }^{c}$ Number of penetrations.

${ }^{d}$ Number of sites.

${ }^{e}$ Measured using a broadband $(3-12 \mathrm{kHz})$ stimulus.

${ }^{f}$ Includes combined widths when curves had multiple peaks (see Fig. 9).

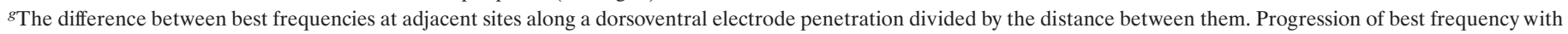

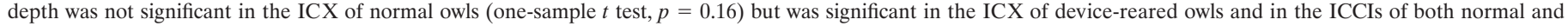
device-reared owls $(p<0.001)$.

${ }^{h}$ The difference between best ILDs at adjacent sites along a dorsoventral electrode penetration divided by the distance between them.

*ICCIs and ICX totals differed significantly (unpaired $t$ test, $p<0.01$ ).

Table 2. Acoustic effects of the device ${ }^{a}$

\begin{tabular}{|c|c|c|c|c|c|c|c|c|}
\hline \multirow{2}{*}{$\begin{array}{l}\text { Frequency } \\
(\mathrm{kHz})\end{array}$} & \multicolumn{4}{|c|}{ Change in timing $(\mu \mathrm{sec})^{b}$} & \multicolumn{4}{|c|}{ Change in level $(\mathrm{dB})^{c}$} \\
\hline & $n$ & Median & Min & Max & $n$ & Median & Min & Max \\
\hline 4 & 5 & -65 & -91 & -33 & 4 & -9 & -2 & -12 \\
\hline 6 & 5 & -29 & -54 & -12 & 4 & -16 & -10 & -23 \\
\hline 8 & 5 & -6 & -18 & 53 & 4 & -15 & -8 & -20 \\
\hline
\end{tabular}

${ }^{a}$ Cochlear microphonic measurements of the difference in the timing and level of sounds reaching the eardrum before versus after device insertion, with the sound source located at $0^{\circ} \mathrm{az}, 0^{\circ}$ el (data from Gold and Knudsen, 1999).

${ }^{b}$ Time difference nearest $0 \mu \mathrm{sec}$ for the measured phase difference; negative values indicate delays.

${ }^{c}$ Negative values indicate attenuations.

stimulus and narrowband (1 kHz bandwidth) stimuli centered on frequencies between 3 and $9 \mathrm{kHz}$. These data, which are from sites with visual RFs between $\mathrm{L} 25^{\circ}$ and $\mathrm{R} 25^{\circ}$ azimuth and $\pm 15^{\circ}$ elevation, have been reported previously (Gold and Knudsen, 2000) and are summarized below.

\section{Frequency dependence of ITD tuning at individual sites}

In normal owls, sounds produce ITD values that are nearly constant across frequency for most of frontal space (Knudsen et al., 1991). Accordingly, the best ITDs that we measured at single sites did not vary substantially with stimulus frequency. Narrowband ITD tuning curves were periodic, reflecting a comparison of interaural phase by circuits earlier in the ITD pathway (Sullivan and Konishi, 1986; Carr and Konishi, 1988, 1990). Nevertheless, the narrowband ITD tuning curves measured at individual sites using different center frequencies were aligned such that each had a peak at a common best ITD, regardless of stimulus frequency. As shown in Figure 2 $A$, these tuning curves, measured over a 2-6 $\mathrm{kHz}$ range of center frequencies, aligned to within $24 \mu \mathrm{sec}$ for all sites tested ( $n=27)$. Indeed, the best ITD for $4 \mathrm{kHz}$ typically matched the best ITDs measured with higher frequency, narrowband stimuli, up to $9 \mathrm{kHz}$ (Fig. 2B).
In contrast, owls wearing the device experience ITD values that depend strongly on frequency (Table 2). Accordingly, the best ITDs that we measured at single sites in device-reared owls varied substantially with stimulus frequency. Narrowband ITD tuning curves were typically periodic, as in normal owls, but for most sites they did not have mutually aligned peaks when measured with different stimulus frequencies. For 77 sites, narrowband best ITDs, measured using a $1-6 \mathrm{kHz}$ range of stimulus center frequencies, had ranges of up to $145 \mu \mathrm{sec}$ (Fig. 2C). The differences between the best ITDs at $4 \mathrm{kHz}$ and those measured using higher frequencies were in many cases $>75 \mu$ sec (Fig. 2D); for frequencies near 7 and $8 \mathrm{kHz}$, this quantity was significantly greater than normal (Mann-Whitney $U$ test, $p<0.01$ ).

\section{Map of ITD}

Device-induced changes in the tectal map of ITD were quantified by comparing unit best ITDs with predicted normal values for both broadband and narrowband stimuli (Table 3). For broadband stimuli, predicted normal best ITDs were based on the systematic relationship between best ITD and visual RF azimuth in normal owls that has been reported previously (Olsen et al., 1989; Brainard and Knudsen, 1993) and is illustrated in Figure 3, 


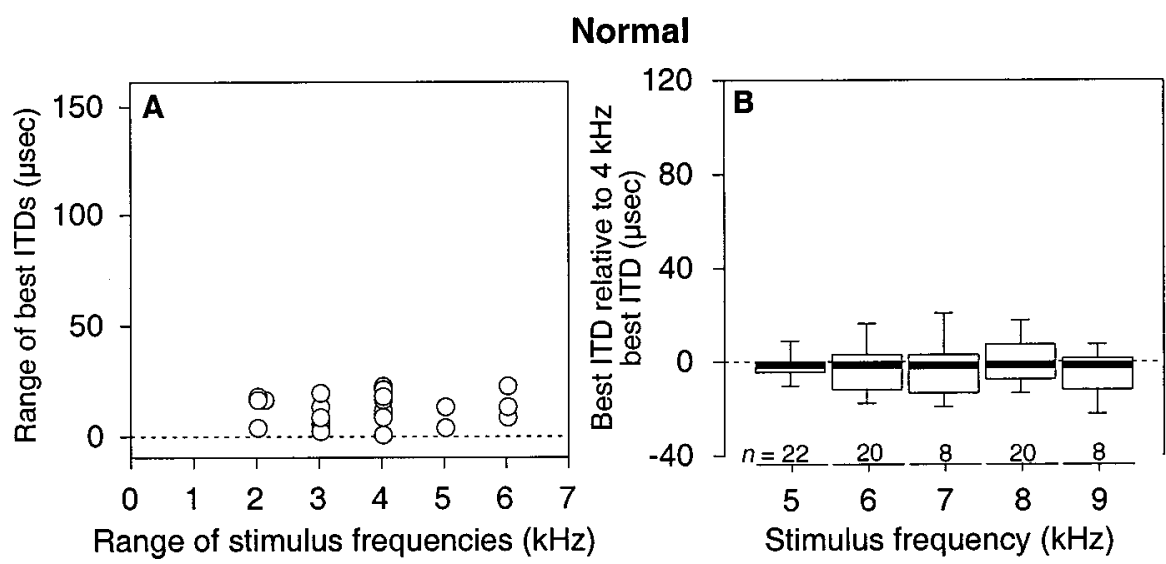

Device-reared
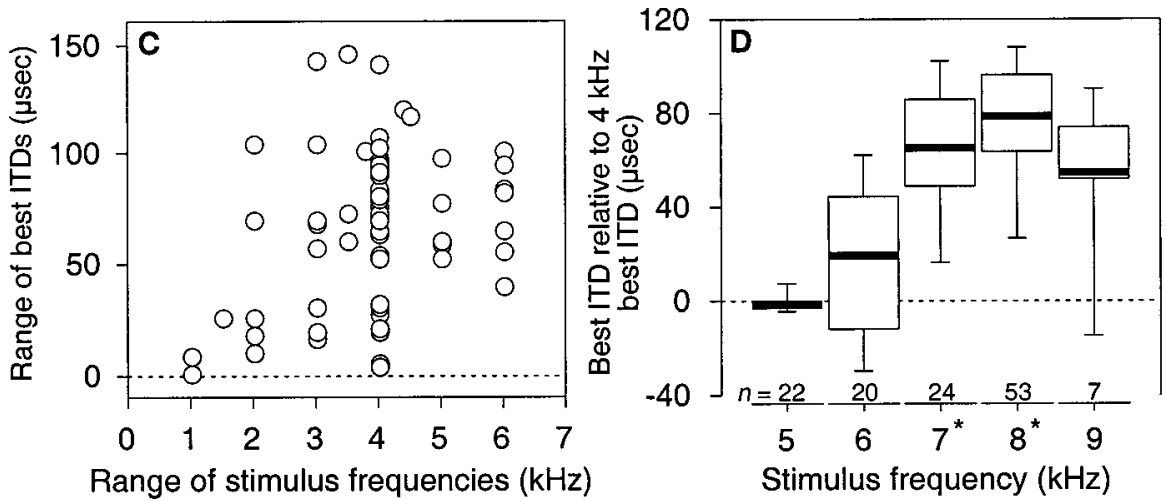

Figure 2. Frequency dependence of ITD tuning in the optic tecta of normal $(A$ and $B)$ and devicereared $(C$ and $D)$ owls (data from Gold and Knudsen, 2000). Analysis is restricted to sites

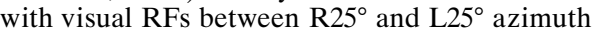
and $\pm 15^{\circ}$ elevation. Best ITDs were measured using narrowband ( $1 \mathrm{kHz}$ bandwidth) stimuli centered on various frequencies at individual tectal sites. $A$, The range of best ITDs measured plotted with respect to the range of center frequencies tested at each site. $B$, The difference between the $4 \mathrm{kHz}$ best ITD and the best ITDs measured at the same site using the given center frequency of the stimulus, binned as indicated. Thick lines, boxes, and bars indicate medians, quartiles, and 10th/90th percentiles, respectively. $C, D$, Data from device-reared owls, plotted as described for $A$ and $B$, respectively. $D$, An asterisk by the stimulus frequency indicates that the data for that frequency differed significantly from the corresponding data in $B$ (Mann-Whitney $U$ test, $p<0.01)$.

Table 3. Frequency-specific ITD tuning in the optic tectum

Best ITD relative to predicted normal ${ }^{a}$

\begin{tabular}{|c|c|c|c|c|c|c|c|c|c|c|c|c|}
\hline \multirow[b]{2}{*}{ Experience } & \multicolumn{3}{|c|}{ Broadband } & \multicolumn{3}{|l|}{$4 \mathrm{kHz}$} & \multicolumn{3}{|l|}{$6 \mathrm{kHz}$} & \multicolumn{3}{|l|}{$8 \mathrm{kHz}$} \\
\hline & Median & $\mathrm{IQR}^{b}$ & $n$ & Median & $\mathrm{IQR}^{b}$ & $n$ & Median & $\mathrm{IQR}^{b}$ & $n$ & Median & $\mathrm{IQR}^{b}$ & $n$ \\
\hline Normal & 1 & 11 & 42 & -1 & 16 & 21 & -1 & 10 & 44 & 0 & 11 & 53 \\
\hline Device-reared & $-44^{*}$ & 73 & 206 & $-55^{*}$ & 21 & 91 & $-42^{*}$ & 56 & 52 & $23^{*}$ & 26 & 87 \\
\hline
\end{tabular}

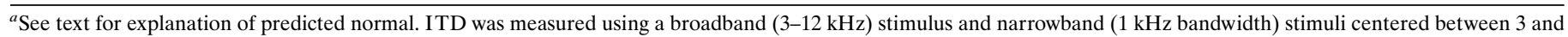
$5 \mathrm{kHz}$ ("4 kHz"), between 5 and $7 \mathrm{kHz}$ ("6 kHz"), and between 7 and $9 \mathrm{kHz}$ (" $8 \mathrm{kHz} ")$.

${ }^{b} \mathrm{IQR}$, Interquartile range.

*Significantly different from normal (Mann-Whitney $U$ test, $p<0.01$ ).

$A$ and $B$. For narrowband stimuli (Fig. 3C), predicted normal best ITD was defined as the frequency-specific, acoustic ITD produced in normal owls by a source located at the center of the visual RF of the given site (data from Knudsen et al., 1991). In normal owls, narrowband best ITDs matched these predicted values to within $30 \mu \mathrm{sec}$ at all sites tested.

Device rearing caused frequency-dependent shifts in the tectal map of ITD (Fig. 3D). For broadband stimuli, ITD tuning curves often had multiple peaks, and best ITDs were shifted significantly (Mann-Whitney $U$ test, $p<0.01$ ) from predicted normal values by a median value of $-44 \mu \mathrm{sec}$ (Fig. $3 E$ ). For narrowband stimuli, best ITDs were also shifted from predicted normal values (Fig. $3 F$ ). The direction and magnitude of these shifts depended on the stimulus frequency, with median shifts of $55 \mu \mathrm{sec}$ toward openear leading at $4 \mathrm{kHz}$ and $23 \mu \mathrm{sec}$ toward affected-ear leading at 8 $\mathrm{kHz}$. These shifts matched roughly the effects of the device on sound timing (Fig. $3 F$, shaded region; Table 2).

\section{Frequency responses}

Frequency-response functions measure the effect of stimulus frequency on the strength of neural responses. When these functions are measured using dichotic stimuli with constant ITD and ILD values, they reflect both the spectral sensitivity of a unit and its tuning for ITD and ILD. The effect of ITD and ILD tuning on frequency-response functions is minimal for most neurons in the optic tecta of normal owls, however, because they are typically tuned to values of ITD and ILD that do not vary with stimulus frequency. In contrast, tectal neurons in device-reared owls are tuned to values of ITD and ILD that depend strongly on stimulus frequency (Gold and Knudsen, 2000). Therefore, to account for possible effects of stimulus ITD and ILD on frequency-response functions, we assessed responses to narrowband $(1 \mathrm{kHz}$ bandwidth) stimuli using the best ITD and best ILD measured for each stimulus. 
Figure 3. Representation of ITD in the optic tecta of normal $(A-C)$ and devicereared $(D-F)$ owls (data from Gold and Knudsen, 2000). Analysis is restricted to sites with visual $\mathrm{RFs}$ between $\mathrm{R} 25^{\circ}$ and L $25^{\circ}$ azimuth and $\pm 15^{\circ}$ elevation. $A$, Best ITD for a broadband $(3-12 \mathrm{kHz})$ stimulus and narrowband (1 kHz bandwidth) stimuli centered on 4,6 , and $8 \mathrm{kHz}$ plotted as a function of visual RF azimuth. The line is a linear fit to the broadband data $(y=$ $2.4 x+0.2, r^{2}=0.89$; ANOVA, $\left.p<0.01\right)$. $B$, Histogram of the residuals of broadband best ITDs relative to the linear fit in A. $C$, Best ITD measured using a $1 \mathrm{kHz}-$ wide stimulus relative to the predicted normal value plotted as a function of the center stimulus frequency. Predicted normal was defined as the acoustic ITD produced in normal owls by a source located at the center of the visual RF of the site for the given frequency (acoustic data from Knudsen et al., 1991). $D-F$, Data from device-reared owls, plotted as described for $A-C$, respectively. $D$, The bold crosses represent data from sites with broadband ITD tuning curves with two discrete peaks. The dashed line indicates the normal, broadband regression from $A$. $E$, For sites that exhibited two discrete ITD response peaks, both peaks are included in this plot. Median $=-44 \mu \mathrm{sec}$ (downward arrowhead). $F$, The dashed line and shaded region represent the median values and ranges, respectively, of phaseequivalent shifts in the timing of sound reaching the right eardrum caused by insertion of the acoustic filtering device (cochlear microphonic measurements from five owls; Gold and Knudsen, 1999).

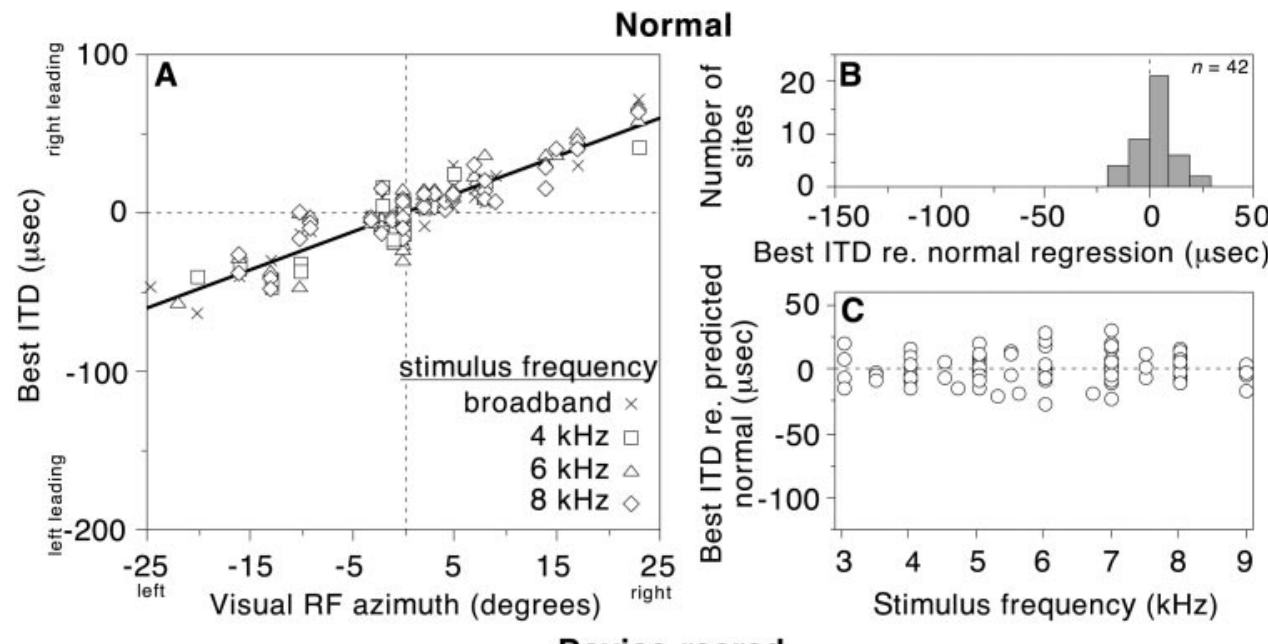

Device-reared

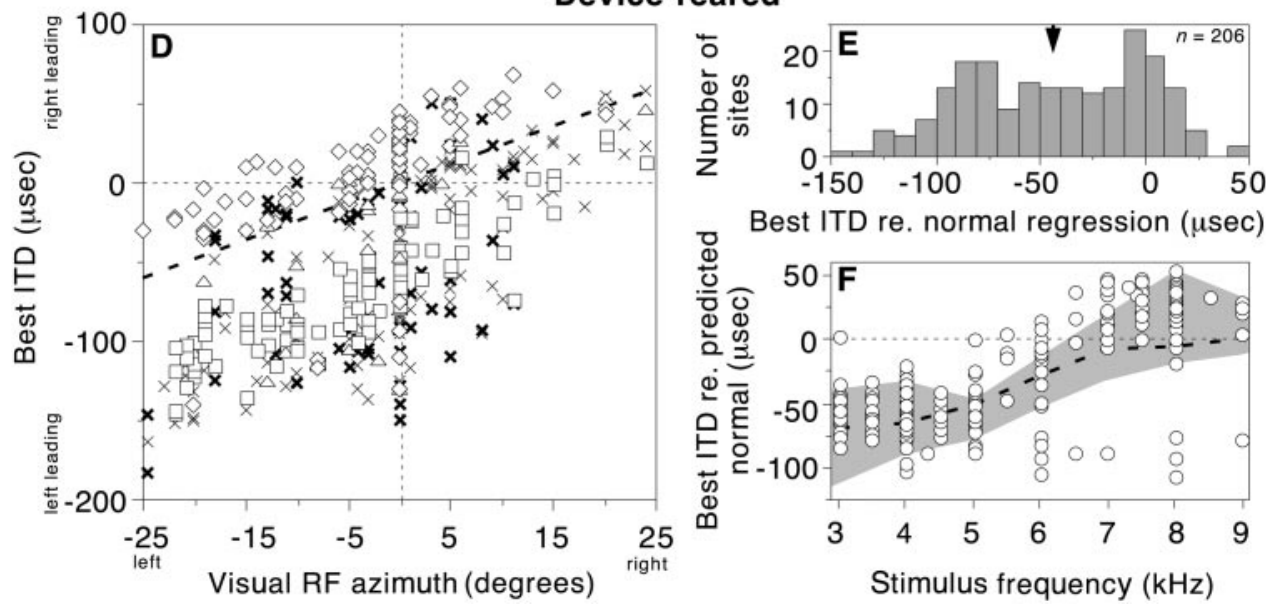

Device rearing changed the spectral sensitivity of neurons in the optic tectum (Gold and Knudsen, 1999, 2000). In normal owls, tectal neurons responded robustly to all frequencies between $\sim 4$ and $9 \mathrm{kHz}$, with the strongest responses to stimuli near $6 \mathrm{kHz}$ (Fig. 4A), which is consistent with previously published reports (Knudsen, 1984a; Olsen et al., 1989). In device-reared owls, tectal neurons also responded robustly to stimuli near 4 and $8 \mathrm{kHz}$. However, responses to stimuli near 6 and $7 \mathrm{kHz}$ were typically $<40 \%$ of the maximum response elicited by any narrowband stimulus at a given site. This relative response level was significantly below that observed in the normal owls (Fig. 4B).

\section{External nucleus of the inferior colliculus}

Like neurons in the optic tectum, neurons in the ICX are broadly tuned for frequency (Knudsen, 1984b). Therefore, we assessed ITD tuning at individual ICX sites using a broadband stimulus and narrowband ( $1 \mathrm{kHz}$ bandwidth) stimuli centered on various frequencies between 3.5 and $8 \mathrm{kHz}$. These data indicate deviceinduced changes in ITD and frequency tuning similar to those found in the optic tectum.

\section{Frequency dependence of ITD tuning at individual sites}

Figure 5 illustrates broadband and narrowband ITD tuning curves measured at individual sites in the ICX of a normal and a device-reared owl. For the site in the normal owl (Fig. 5A), the broadband ITD tuning curve had a single peak with a best value of $-48 \mu \mathrm{sec}$. Narrowband stimuli centered on frequencies between 3.5 and $7.5 \mathrm{kHz}$, all of which elicited robust responses, produced ITD tuning curves with best values between -34 and $-40 \mu \mathrm{sec}$. In contrast, for the site in the device-reared owl (Fig. $5 B$ ), the broadband ITD tuning curve had two peaks, with best values of -171 and $-35 \mu \mathrm{sec}$, respectively. Moreover, narrowband ITD tuning varied substantially with stimulus center frequency: for stimuli centered on 3.5 and $4.5 \mathrm{kHz}$, best ITDs were near $-100 \mu \mathrm{sec}$; for stimuli centered on $5.5 \mathrm{kHz}$, no responses could be elicited at any ITD (range of ILDs tested: -24 to $24 \mathrm{~dB}$ ); and for stimuli centered on 6.5 and $7.5 \mathrm{kHz}$, ITD tuning curves, which were periodic because of a comparison of interaural phase earlier in the pathway, had best values near $-40 \mu \mathrm{sec}$.

As the examples in Figure 5 illustrate, device rearing affected the frequency dependence of ITD tuning in the ICX. Figure $6 \mathrm{~A}$ shows the relationship between narrowband best ITD and stimulus center frequency for individual sites in normal owls. In all cases, narrowband best ITD was nearly constant as a function of center frequency: narrowband best ITDs measured over a 3 or 4 $\mathrm{kHz}$ range of center frequencies between 3.5 and $8 \mathrm{kHz}$ were within a $28 \mu \mathrm{sec}$ range at individual sites (Fig. $6 \mathrm{~B}$ ). At these sites, best ITDs at $4 \mathrm{kHz}$ were nearly the same as best ITDs measured using narrowband stimuli centered at higher frequencies (Fig. $6 C)$. This ITD tuning matches the frequency-independent acoustic ITDs that correspond to the regions of frontal space that these neurons represent (Knudsen et al., 1991).

In contrast, narrowband best ITD varied substantially with stimulus center frequency for individual sites in the ICX of device-reared owls (Fig. 6D). Narrowband best ITDs measured 

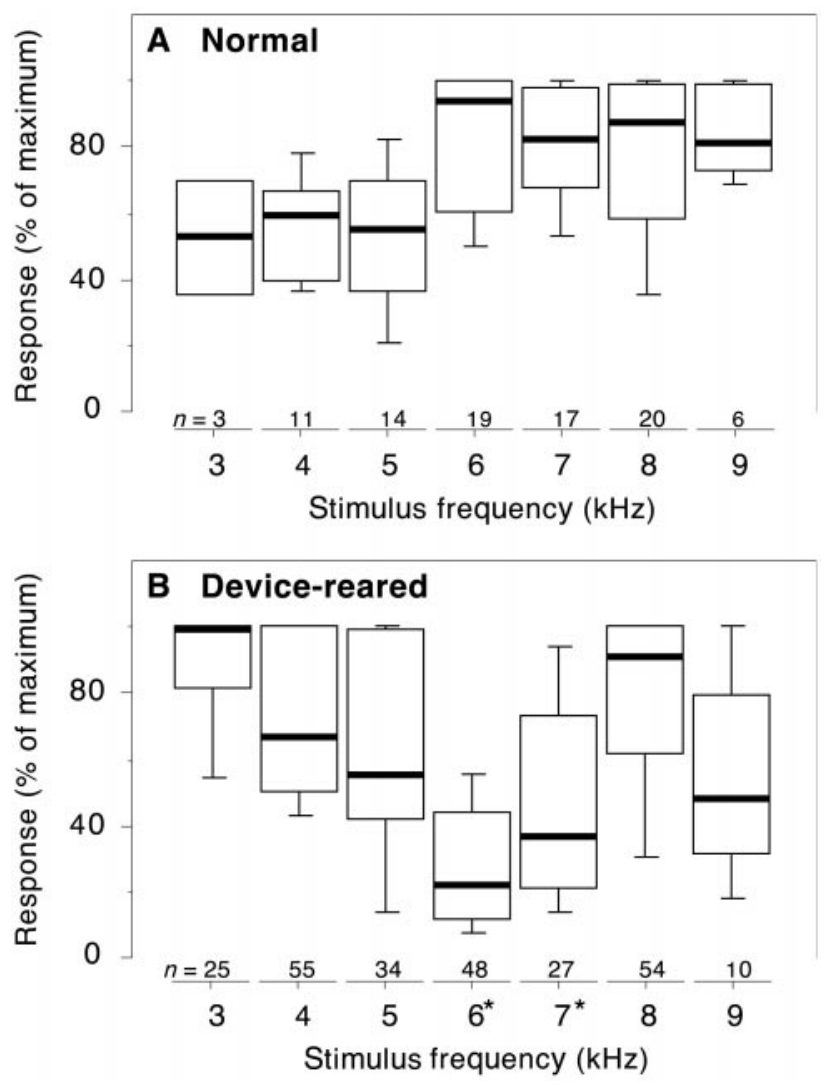

Figure 4. Frequency responses in the optic tecta of normal $(A)$ and device-reared $(B)$ owls (data from Gold and Knudsen, 2000). Analysis is restricted to sites with visual RFs between $\mathrm{R} 25^{\circ}$ and $\mathrm{L} 25^{\circ}$ azimuth and $\pm 15^{\circ}$ elevation. Strength of response to the best ITD/ILD pair for a narrowband (1 kHz bandwidth) stimulus, normalized to the maximum response elicited by any such narrowband stimulus at the same recording site, is plotted as a function of the center frequency of the stimulus. Thick lines, boxes, and bars indicate medians, quartiles, and 10th/90th percentiles, respectively. $B$, An asterisk by the stimulus frequency indicates that the data for that frequency differed significantly from the corresponding data in $A$ (Mann-Whitney $U$ test, $p<0.01$ ).

over a $2-4 \mathrm{kHz}$ range covered an $8-100 \mu$ sec range (Fig. 6E). These ranges reflected significant changes in the relative values of best ITDs measured at individual sites using different center frequencies (Fig. $6 F$ ). This abnormal frequency dependence of ITD tuning was consistent with the acoustic effects of the device (Table 2).

\section{Map of ITD}

In the optic tectum, broadband and narrowband ITD tuning at a given site can be predicted reliably from the location of the visual RF (Olsen et al., 1989; Gold and Knudsen, 2000). In the ICX, there is no such physiological marker of predicted normal ITD tuning. Instead, the map of ITD in the ICX has been determined by correlating best ITDs with recording site locations reconstructed from electrolytic lesions (Brainard and Knudsen, 1993). An example of this type of lesion is shown in Figure $7 A$, which depicts the reconstruction of a recording site in the lateral portion of the right ICX in a normal owl with a best ITD of $-50 \mu$ sec. A summary of lesion reconstruction data from normal owls is shown in Figure $7 B$, in which broadband best ITD is plotted as a function of rostrocaudal location in the ICX of normal owls. These data show that broadband best ITD progresses systematically along the rostrocaudal axis of the ICX (Fig. 1B), such that

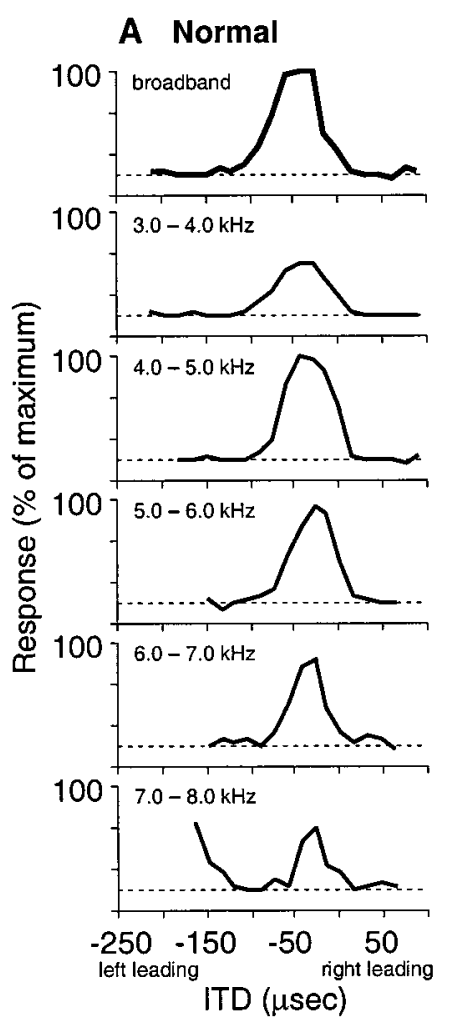

B Device-reared

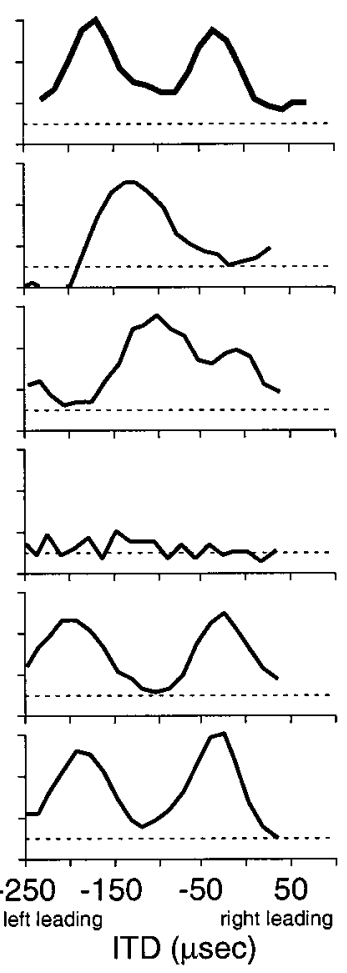

Figure 5. Frequency-specific ITD tuning for a site in the ICX of a normal $(A)$ and a device-reared $(B)$ owl. Broadband (3-12 kHz, curves shown in bold) responses were normalized relative to the maximum response elicited with the broadband stimulus at that site. Narrowband (the range of stimulus frequencies is shown for each curve) responses were normalized relative to the maximum response elicited with any narrowband stimulus at that site.

rostral portions of the nucleus represent values near $0 \mu \mathrm{sec}$, which are produced by sources located in frontal space, and progressively caudal portions of the ICX represent increasingly contralateral-ear-leading values (note that in Fig. $7 B, D, E$, best ITDs are plotted as ipsilateral- and contralateral-ear-leading values). This representation of broadband ITD holds true for narrowband ITD as well, because broadband best ITDs closely match narrowband best ITDs at individual sites in normal owls (Table 4).

In device-reared owls, reconstruction of electrolytic lesions revealed abnormal representations of both broadband and narrowband ITD in the ICX. Figure $7 C$ depicts the reconstruction of a recording site in the ICX of a device-reared owl. As documented in Figure 7, $D$ and $E$, and Table 4, lesion-reconstruction data showed that both broadband and narrowband best ITDs were shifted relative to the normal regression of broadband best ITD on rostrocaudal location in the ICX (from Fig. 7B). On average, the shifts in the left and right ICX were 63 and $52 \mu \mathrm{sec}$, respectively, toward open-ear leading for stimuli near $4 \mathrm{kHz}$ and 8 and $11 \mu \mathrm{sec}$, respectively, in the opposite direction for stimuli near $8 \mathrm{kHz}$. These shifts were similar to those observed in the tectum (Table 3) (Gold and Knudsen, 2000) and correspond reasonably well with the average acoustic effects of the device (Table 2).

\section{Frequency responses}

Frequency-response properties were abnormal in the ICX of device-reared owls. Figure 8 depicts frequency-response func- 


\section{Normal}
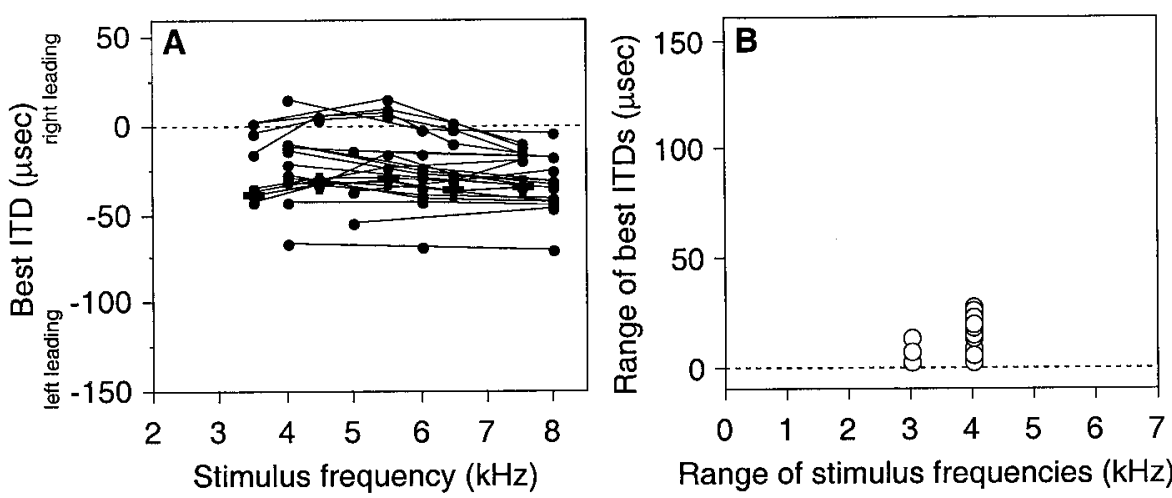

Range of stimulus frequencies $(\mathrm{kHz})$

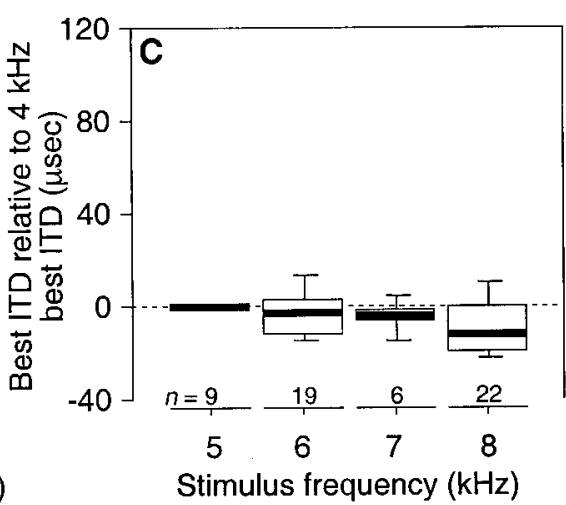

Device-reared
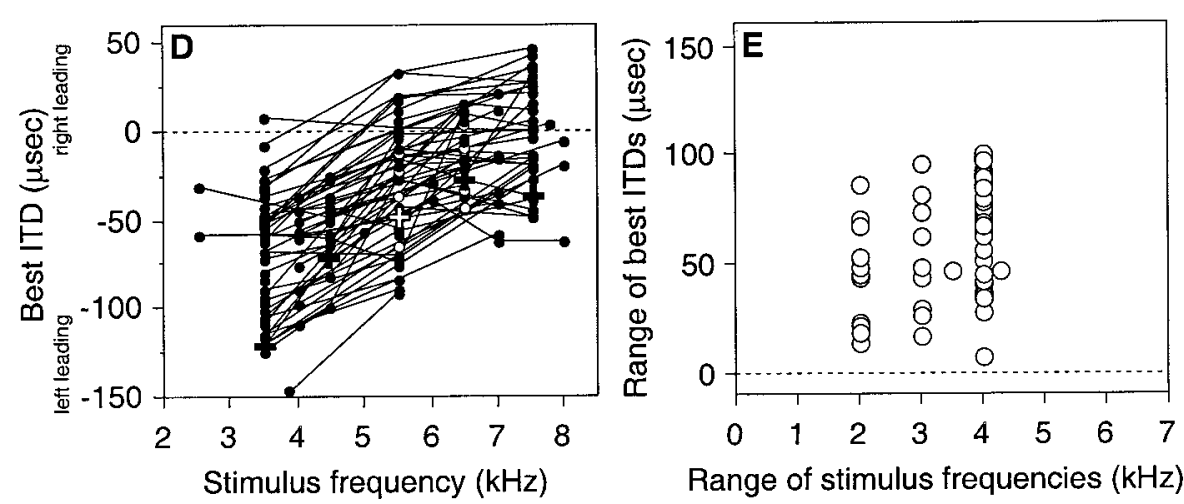

Figure 6. Frequency dependence of ITD tuning in the ICX of normal $(A-C)$ and device-reared $(D-F)$ owls. $A$, Best ITD for narrowband $(1 \mathrm{kHz}$ bandwidth) stimuli plotted as a function of the center frequency of the stimulus. Each line represents data from a single recording site. Crosses represent data from Figure $5 A$. $B$, For each line shown in $A$, the range of best ITDs plotted with respect to the range of stimulus center frequencies tested. $C$, The difference between the $4 \mathrm{kHz}$ best ITD and the best ITDs measured at the same site using the given center frequency, binned as indicated. Thick lines, boxes, and bars indicate medians, quartiles, and 10th/90th percentiles, respectively. $D-E$, Data from device-reared owls, plotted as described for $A-C$, respectively. $D$, Crosses represent data from Figure $5 B$. The open symbols represent frequencies that were tested but did not elicit strong enough responses to measure ITD tuning at the given site; each of these symbols is drawn on the line connecting data collected from the given site. $F$, An asterisk by the stimulus frequency indicates that the data for that frequency differed significantly from the corresponding data in $C$ (Mann-Whitney $U$ test, $p<0.01$ ).

tions measured in the ICX of normal and device-reared owls using dichotic stimuli with the broadband best ITD and best ILD for the given site. In normal owls, these functions typically had a single peak with a median best frequency of $6.4 \mathrm{kHz}$ [with an interquartile range (IQR) of $1.0 \mathrm{kHz}$ ] that did not vary with dorsoventral depth (Fig. 8A,B; Table 1). In contrast, frequencyresponse functions measured in device-reared owls had either multiple peaks (Fig. $8 C$ ) or peaks with best values that varied with stimulus ITD for 11 of 63 sites. The distribution of best frequencies from all peaks for all recording sites in the ICX of devicereared owls was roughly bimodal, with peaks at $\sim 3.5$ and $7.0 \mathrm{kHz}$ (Fig. 8D). Unlike in normal owls, there was also a tendency for best frequency to increase with dorsoventral depth (Fig. $8 C$; Table 1).

However, as in the optic tectum, these frequency-response functions measured using constant ITD and ILD values reflected both the spectral sensitivity and the binaural tuning of units in the ICX. To account for possible effects of stimulus ITD and ILD on these measurements, we also assessed frequency responses using narrowband (1 $\mathrm{kHz}$ bandwidth) stimuli with the best ITD and best ILD optimized for each frequency range. In normal owls, these frequency-response functions indicated robust responses to all stimuli between 3.5 and $8.0 \mathrm{kHz}$, with strongest responses to stimuli above $5 \mathrm{kHz}$ (responses from a single site are illustrated in Fig. $9 A$; data from all sites tested are summarized in Fig. 9B).

Frequency-response functions measured using the best ITD and best ILD for each narrowband ( $1 \mathrm{kHz}$ bandwidth) stimulus were abnormal in device-reared owls. For the site illustrated in Figure $9 C$, the responses to stimuli near 4 and $8 \mathrm{kHz}$ were much stronger than the responses to stimuli near $6 \mathrm{kHz}$. In general, responses to stimuli below $5 \mathrm{kHz}$ and above $7 \mathrm{kHz}$ were robust, whereas responses to stimuli near 6 and $7 \mathrm{kHz}$ were weak. In fact, responses to stimuli near 6 and $7 \mathrm{kHz}$ were typically $<60 \%$ of the maximum response elicited by any narrowband stimulus at the given site, a difference from normal that was statistically significant (Mann-Whitney $U$ test, $p<0.01$ ) (Fig. 9D). These data indicate that device rearing modified the spectral sensitivity of neurons in the ICX.

\section{Short-latency shifted responses}

The shifts in ITD tuning measured in the ICX of device-reared owls could result from plasticity in the ascending ITD pathway from the ICC or from plasticity in other, less direct pathways such as from the forebrain or cerebellum. To test the hypothesis that ITD tuning shifts were caused, at least in part, by plasticity in the direct, ascending pathway from the ICCls, we assessed frequency- 

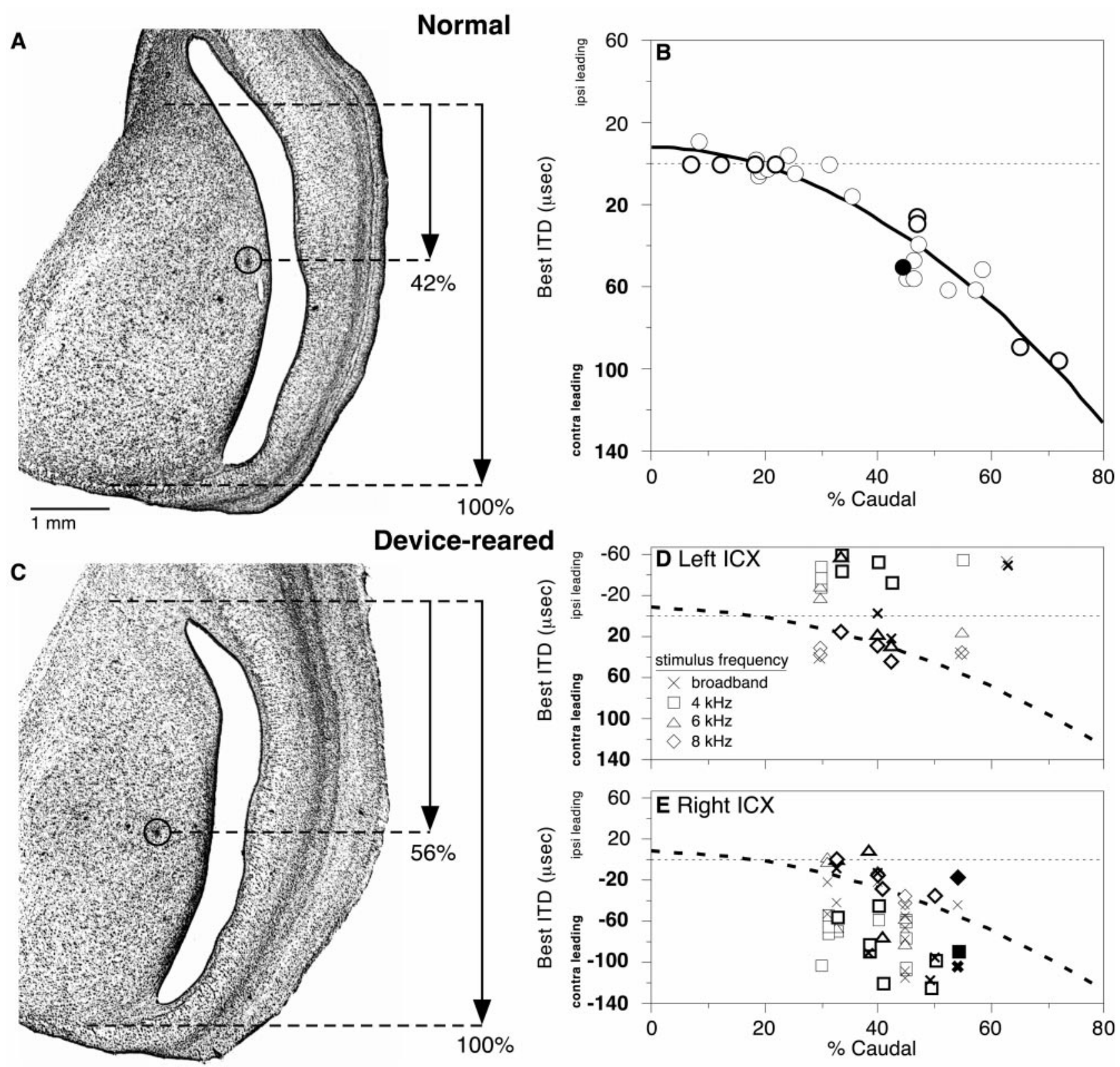

Figure 7. Representation of ITD in the ICX of normal $(A, B)$ and device-reared $(C-E)$ owls. $A$, Nissl-stained, horizontal section through the ICX showing a recording site, marked by a lesion (circled), at which ITD tuning was measured. Recording location was quantified as the percentage of distance from the rostral to the caudal pole of the ICX. At this site, the broadband best ITD $=-50 \mu$ sec; narrowband best ITDs $=-54$ and $-46 \mu$ sec for 4 and $8 \mathrm{kHz}$ stimuli, respectively. $B$, Best ITD for a broadband stimulus as a function of rostrocaudal location in the ICX. Data from the left and right side of the brain are included. Plain and bold labels represent ipsilateral- and contralateral-ear-leading values, respectively. Thin circles represent data from Brainard and Knudsen (1993). The filled circle indicates data from the site shown in $A$. The solid line is a second-order polynomial fit to the data $\left(r^{2}=0.92\right.$; ANOVA, $\left.p<0.001\right)$. $C$, Reconstruction of an ICX recording site in a device-reared owl. At this site, the broadband best ITD $=-95 \mu$ sec; narrowband best ITDs $=-97$ and $-35 \mu \mathrm{sec}$ for 4 and $8 \mathrm{kHz}$ stimuli, respectively. $D, E$, Best ITD as a function of rostrocaudal location in the left ( $D$ ) and right $(E)$ ICX of device-reared owls. Stimulus frequencies refer to the center frequency of a narrowband (1 kHz bandwidth) stimulus or to a broadband (3-12 kHz) stimulus. Recording site locations were determined either by recovery of lesions (bold symbols) or by estimation based on microdrive coordinates relative to recovered lesions (thin symbols). Plain and bold labels represent ipsilateral- and contralateral-ear-leading values, respectively. The filled symbols in $E$ indicate data from the site shown in $C$. The dashed line in each panel is the fit to normal data (see $A$ ).

specific ITD tuning measured in the earliest responses of ICX neurons ( $<10 \mathrm{msec}$ after stimulus) (Fig. 10).

We compared narrowband ITD tuning for 4 and $8 \mathrm{kHz}$ stimuli derived from early versus late responses. For $4 \mathrm{kHz}$ stimuli, best ITD could be determined within the first $8 \mathrm{msec}$ after stimulus onset for 6 of 45 sites. For these sites, the best ITD measured during this early part of the response was not significantly different from the best ITD measured during the remaining $92 \mathrm{msec}$ (paired $t$ test, $p=0.41$ ). For 17 of the remaining 39 sites, best ITD could be determined within $10 \mathrm{msec}$ after stimulus onset. For these sites, the best ITD measured from the early responses was slightly more right-ear leading (and thus less adaptively shifted), by $9 \pm 14 \mu \mathrm{sec}$ (mean $\pm \mathrm{SD}$ ), than the best ITD measured from the remainder of the response $(p=0.02)$. For 8 $\mathrm{kHz}$ stimuli, best ITD could be determined within the first $8 \mathrm{msec}$ after stimulus onset for 25 of 45 sites and within the first $10 \mathrm{msec}$ 
Table 4. Frequency-specific ITD tuning in the ICX

Best ITD relative to predicted normal ${ }^{a}$

\begin{tabular}{|c|c|c|c|c|c|c|c|c|c|c|c|c|}
\hline \multirow[b]{2}{*}{ Experience } & \multicolumn{3}{|c|}{ Broadband } & \multicolumn{3}{|l|}{$4 \mathrm{kHz}$} & \multicolumn{3}{|l|}{$6 \mathrm{kHz}$} & \multicolumn{3}{|l|}{$8 \mathrm{kHz}$} \\
\hline & Median & $\mathrm{IQR}^{b}$ & $n$ & Median & $\mathrm{IQR}^{b}$ & $n$ & Median & $\mathrm{IQR}^{b}$ & $n$ & Median & $\mathrm{IQR}^{b}$ & $n$ \\
\hline Normal $^{c}$ & 0 & 10 & 25 & 5 & 11 & 24 & 2 & 8 & 28 & -4 & 8 & 22 \\
\hline Device-reared $^{d}$ & & & & & & & & & & & & \\
\hline Left ICX & $-26^{*}$ & 30 & 8 & $-63^{*}$ & 23 & 8 & $-33^{*}$ & 34 & 6 & 8 & 21 & 6 \\
\hline Right ICX & $-32 *$ & 51 & 19 & $-52^{*}$ & 31 & 19 & -8 & 62 & 8 & $11^{*}$ & 14 & 8 \\
\hline
\end{tabular}

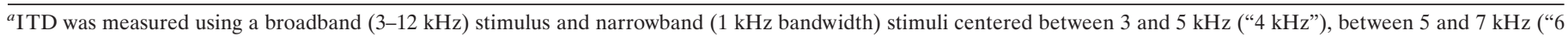

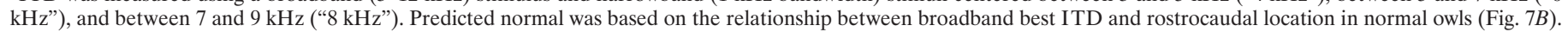
${ }^{b} \mathrm{IQR}$, Interquartile range.

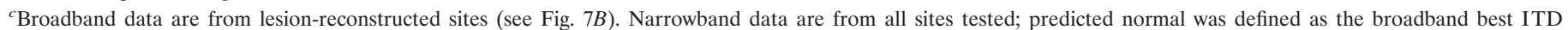
measured at the given site.

${ }^{d}$ Data are from lesion-reconstructed sites (see Fig. $7 D, E$ ).

*Significantly different from normal (Mann-Whitney $U$ test, $p<0.01$ ).

Figure 8. Frequency responses in the ICX of normal $(A, B)$ and device-reared $(C, D)$ owls. $A$, Frequency tuning curves measured at sites in a single dorsoventral penetration through the ICX. The legend indicates depth of the given recording site relative to the most superficial site. In order of increasing dorsoventral depth, the best frequencies were $5.8,6.4$, and $6.5 \mathrm{kHz}$. B, Distribution of best frequencies from 23 sites in four normal owls. For one site, the frequency tuning curve had two peaks; both best values are included. Median $=6.4 \mathrm{kHz}$ (downward arrowhead), IQR $=1.0 \mathrm{kHz}$. $C, D$, Data from devicereared owls, plotted as described for $A$ and $B$, respectively. $C$, At the most superficial site, neurons responded robustly to frequencies between 1 and 4 $\mathrm{kHz}$ and around $7.5 \mathrm{kHz}$. At the middle site, neurons responded only to around $7 \mathrm{kHz}$. At the deepest site, neurons responded best to between 7 and $9 \mathrm{kHz}$ and at $\sim 50 \%$ of maximum between 3 and $7 \mathrm{kHz}$. $D$, For 11 sites, frequency tuning curves either had multiple peaks or a peak that depended on stimulus ITD; best values from all such peaks are included. Median = $5.2 \mathrm{kHz}$ (downward arrowhead), IQR $=3.3 \mathrm{kHz}$.

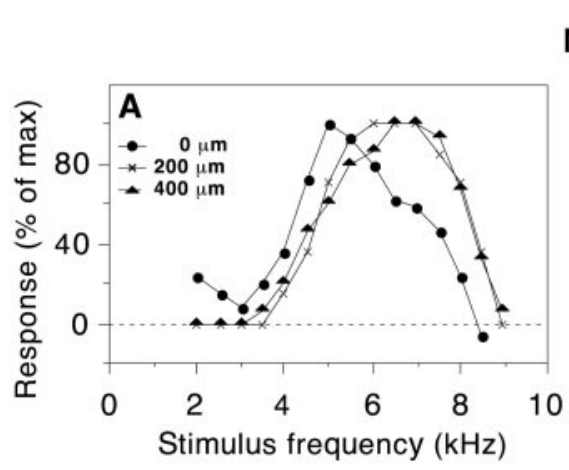

Normal

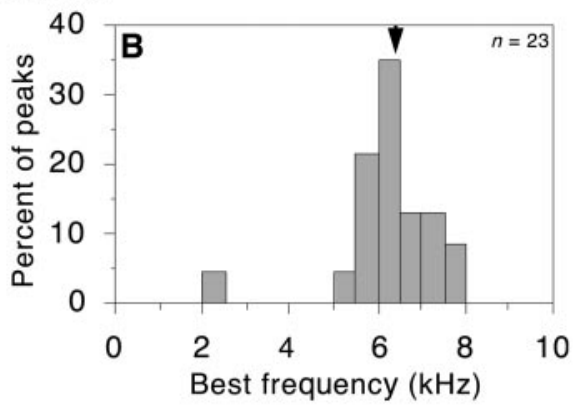

Device-reared
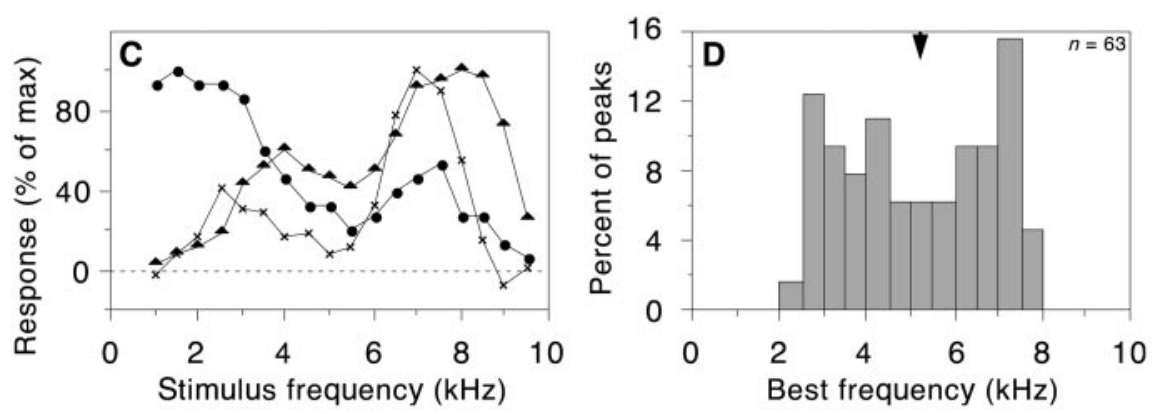

after stimulus onset for six of the remaining sites. For these sites, best ITD measured from the early response did not differ significantly $(p>0.05)$ from the best ITD measured from the remainder of the response.

Thus, for low-frequency stimuli there was in some cases a tendency for late responses to be more shifted than early responses, but this difference could account for only a small fraction of the overall shift of $\sim 60 \mu \mathrm{sec}$. For high-frequency stimuli, there was no difference in ITD tuning between early and late responses. These data are consistent with the hypothesis that plasticity in the representation of ITD occurred in the direct, ascending pathway to the ICX.

\section{Central nucleus of the inferior colliculus, lateral shell subdivision}

Neurons in the ICCls are narrowly tuned for frequency. Therefore, frequency-specific ITD tuning could not be measured at individual ICCls sites using a broad range of frequencies, as it could be in the optic tectum and the ICX. However, neurons in the ICCls are organized with respect to their frequency and ITD tuning (Fig. 11). Neurons aligned approximately in the horizontal plane are tuned to the same frequency. Within such an isofrequency lamina, neurons are organized with respect to their tuning for interaural phase difference, such that the phase equivalent of $0 \mu \mathrm{sec}$ ITD is represented rostrally and more contralateral-earleading values are represented more caudally. Across frequency laminae, neurons are aligned according to their interaural phase difference tuning so that a given value of ITD maximally activates a dorsoventral array of neurons. The ITD represented by these neurons is referred to as the array-specific ITD (Wagner et al., 1987). Therefore, to assess the representation of ITD in the ICCls, we measured ITD tuning along dorsoventral electrode penetrations that traversed populations of neurons that, in normal owls, are tuned to different frequencies but to a single, arrayspecific ITD. These data indicate that device rearing did not substantially affect the representations of ITD and frequency in the ICCls. 


\section{Normal}
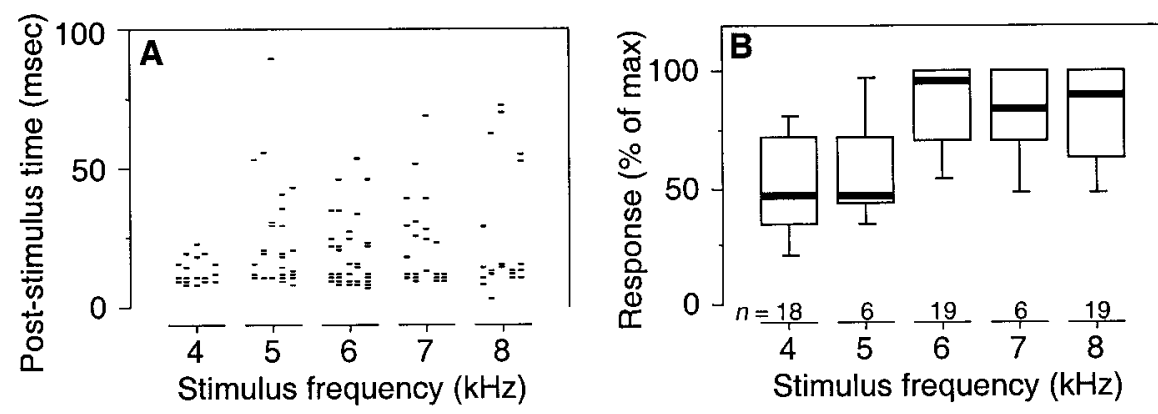

Device-reared
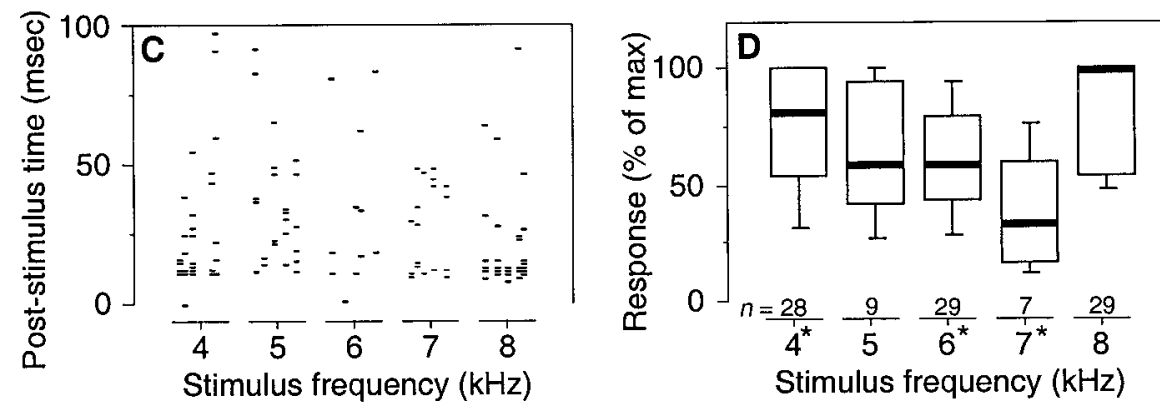

Figure 9. Responses to narrowband $(1 \mathrm{kHz}$ bandwidth) stimuli in the ICX of normal $(A, B)$ and device-reared $(C, D)$ owls. All responses were measured using the best ITD/ILD pair and 20-30 dB above threshold for the given narrowband stimulus. $A$, Raster display representing trial-by-trial responses to a stimulus with the given center frequency during the $100 \mathrm{msec}$ after stimulus onset. Five repetitions per stimulus are shown. $B$, Strength of response to a narrowband stimulus, normalized to the maximum response elicited by any such narrowband stimulus at the same recording site, plotted as a function of the center frequency of the stimulus. Thick lines, boxes, and bars indicate medians, quartiles, and 10th/90th percentiles, respectively. $C, D$, Data from device-reared owls, plotted as described for $A$ and $B$, respectively. $D$, An asterisk by the stimulus frequency indicates that the data for that frequency differed significantly from the corresponding data in $B$ (MannWhitney $U$ test, $p<0.01)$.
Frequency dependence of ITD tuning along individual electrode penetrations

Device rearing did not affect the pattern of ITD tuning along individual dorsoventral electrode penetrations through the ICCls. In both normal and device-reared owls, ICCls neurons had ITD tuning curves that were periodic, reflecting their tuning for interaural phase difference within the narrow ranges of frequencies to which they were tuned. Figure 12 illustrates the frequency and ITD tuning of neurons along a dorsoventral penetration through the ICCls in a normal owl. Best frequency progressed systematically from 2.1 to $7.5 \mathrm{kHz}$ with increasing depth, and best ITD remained relatively constant at $\sim 80 \mu$ sec contralateral-ear leading. Figure 13 illustrates similar data from a device-reared owl. In this case, best frequency progressed systematically from 1.5 to 7.5 $\mathrm{kHz}$, and best ITD remained relatively constant at $\sim 85 \mu \mathrm{sec}$ contralateral-ear leading.

Figure 14 summarizes the relationship between best frequency and best ITD at sites along individual dorsoventral penetrations through the ICCls in normal and device-reared owls. In normal owls (Fig. 14A,B), the variation of best ITDs measured along a given penetration ranged from 0 to $70 \mu \mathrm{sec}$, with a median value of $18 \mu \mathrm{sec}(\mathrm{IQR}=27 \mu \mathrm{sec}, n=39)$. In device-reared owls (Fig. $14 D, E)$, the variation of best ITDs ranged from 1 to $105 \mu \mathrm{sec}$, with a median value of $26 \mu \mathrm{sec}(\mathrm{IQR}=27 \mu \mathrm{sec}, n=80$ ), for penetrations that traversed comparable ranges of frequency representations. Moreover, the differences between the best ITDs of sites tuned to low frequencies (between 3 and $4.5 \mathrm{kHz}$ ) and those tuned to higher frequencies along individual electrode penetrations were not significantly different between normal and devicereared owls (Mann-Whitney $U$ test, $p>0.05$ ) (Fig. 14C,F).

\section{Map of ITD}

The relationship between best ITD and rostrocaudal location in the ICCls has been well characterized for neurons in the $6 \mathrm{kHz}$ isofrequency lamina (Brainard and Knudsen, 1993). Figure 15B shows this relationship in normal owls. We found the same relationship in owls raised with the acoustic device (Fig. 15 $A, C$ ): second-order polynomial fits to the normal and device-reared data did not differ significantly (ANCOVA, $F_{(3,50)}=1.83, p=$ 0.153).

Because the representation of ITD was normal for neurons tuned to $6 \mathrm{kHz}$ in device-reared owls, we assessed the representation of ITD in other frequency laminae with respect to the 6 $\mathrm{kHz}$ representation. Thus, the best ITD in the $6 \mathrm{kHz}$ lamina was the referent for predicting the normal best ITD for all sites in a given penetration. Table 5 summarizes best ITD relative to predicted normal values measured at sites in the ICCls of both normal and device-reared owls, grouped by best frequency. For sites with best frequencies near $4 \mathrm{kHz}$, device rearing shifted best ITDs in the adaptive direction, but the magnitude of the shift could account for only a small portion of the shifts measured in the ICX and optic tectum. For sites with best frequencies near 6 and $8 \mathrm{kHz}$, device rearing did not affect best ITDs. These data implicate the ICX as a primary site of plasticity.

\section{Frequency responses}

Device rearing did not affect frequency responses in the ICCls. In both normal and device-reared owls, ICCls neurons responded robustly to an optimal frequency of between 1 and $9 \mathrm{kHz}$ (examples of responses to best frequencies at different sites in individual electrode penetrations in a normal and a device-reared owl are shown in Fig. $16 A, D)$. These neurons were sharply tuned for frequency, with frequency tuning curves that had similar shapes (Fig. 16B,E) and tuning widths of $\sim 1.5 \mathrm{kHz}$ (Table 1) in both normal and device-reared owls. Moreover, device rearing did not affect the amount of tissue representing individual frequencies along dorsoventral electrode penetrations (Fig. 16C,F). There was no significant difference in the widths of frequency laminae between normal and device-reared owls (unpaired $t$ tests on data from $2 \mathrm{kHz}$-wide bins of best frequency between 3 and $9 \mathrm{kHz}, p>$ $0.05)$. Noticeably absent was any device-induced change in the 

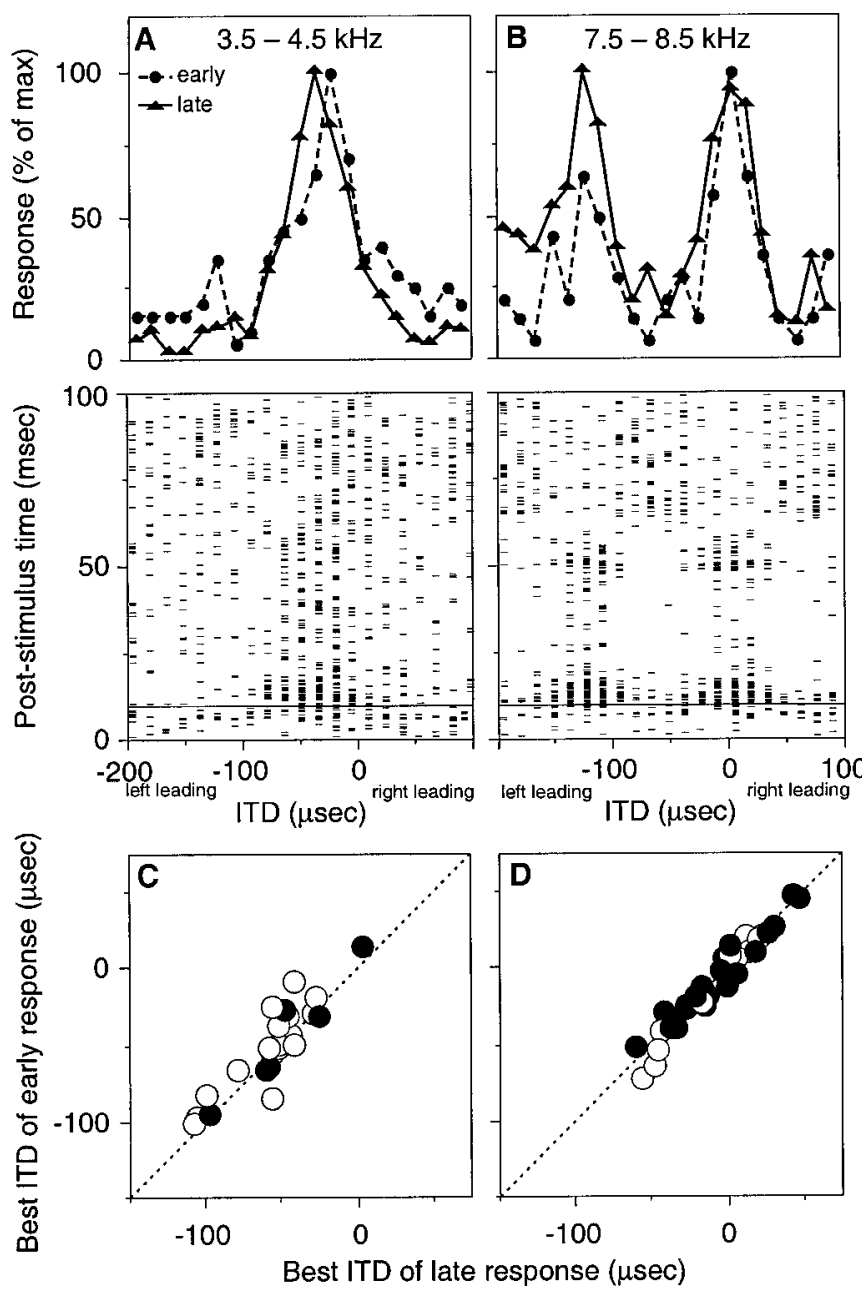

Figure 10. ITD tuning of early versus late responses in the ICX of device-reared owls. $A, B$, Responses as a function of stimulus ITD (top) and post-stimulus time (bottom). The ITD tuning curves were measured from the first $10 \mathrm{msec}$ post-stimulus time (indicated with a horizontal line on the raster plot) or from the remainder of the responses. Data are from a single recording site in the ICX, using narrowband stimuli as indicated. $C, D$, For sites in the ICX of device-reared owls, best ITD calculated from the earliest part of the response plotted as a function of the best ITD calculated from the remainder of the response. Data are indicated separately for sites at which ITD tuning could be determined within the first $8 \mathrm{msec}$ of stimulus onset () or within the first $10 \mathrm{msec}$ of stimulus onset $(\bigcirc)$. The dashed lines indicate no difference between early and late best ITDs. $C$, Narrowband stimuli centered between 3 and $5 \mathrm{kHz}$. $D$, Narrowband stimuli centered between 7 and $9 \mathrm{kHz}$.

responses of ICCls units tuned to frequencies near $6 \mathrm{kHz}$, as was found in the optic tectum (Fig. 4) and the ICX (Figs. 8, 9).

\section{Near the ICC-ICX border}

When recording near the boundary between the ICCls and the ICX in normal and device-reared owls, we found combinations of electrode position, frequency tuning properties, progression of best ILDs, and latencies that were partially consistent with properties of neurons from each nucleus. For example, 25 dorsoventral penetrations through the IC of device-reared owls contained sites with broad frequency tuning (median tuning width $>3 \mathrm{kHz}$ ), followed by a series of sites that had narrow frequency tuning curves with best values that increased systematically. Reconstructions of lesions from four of these penetrations revealed that they

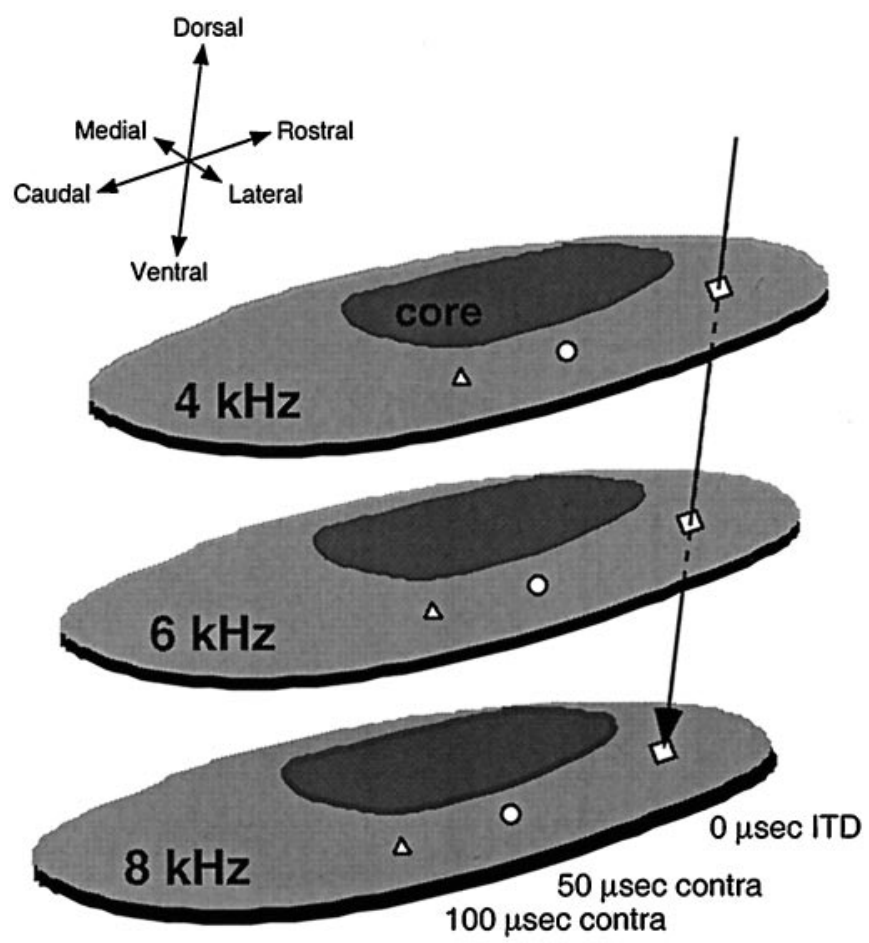

ICC lateral shell

Figure 11. Schematic of the representation of ITD and frequency in the ICCls. Neurons in the ICCls are narrowly tuned for frequency, the value of which increases systematically along the dorsoventral axis of the nucleus. Within each isofrequency lamina, neurons are tuned for interaural phase difference, but a single ITD maximally excites a dorsoventrally aligned array of neurons. Our electrode penetrations (arrow) progressed along this iso-ITD axis.

were located 400-600 $\mu \mathrm{m}$ from the lateral border of the ICCcore, which placed them near the ICCls-ICX border (Wagner et al., 1987; Takahashi and Konishi, 1988; Takahashi et al., 1989; Brainard and Knudsen, 1993).

We found that in this ICC-ICX border region, device rearing caused frequency-dependent shifts in ITD tuning that were intermediate between those measured in the ICCls and those measured in the ICX (Fig. 17). For sites that had narrow frequency tuning curves with best values that progressed systematically toward higher values within a single penetration, we compared narrowband best ITDs across best frequencies (Fig. 17A), as was done in the ICCls. For these penetrations, best ITDs had a 1-26 $\mu \mathrm{sec}$ range, with a median range of $13 \mu \mathrm{sec}(n=19)$ (Fig. $17 C$, open symbols). Alternatively, for sites with broad frequency tuning, we measured narrowband best ITDs using several different narrowband stimuli centered on a $2-4 \mathrm{kHz}$ range of frequencies (Fig. 17B), as was done in the ICX. For these sites, best ITDs had a $2-48 \mu \mathrm{sec}$ range, with a median range of $26 \mu \mathrm{sec}(n=22)$ (Fig. 17C, closed symbols). The difference between best ITDs at 4 and $8 \mathrm{kHz}$, determined either at single sites with narrowband stimuli or at different sites within a single penetration, had a median value of $17 \mu \mathrm{sec}(\mathrm{IQR}=15 \mu \mathrm{sec}, n=21)$.

\section{DISCUSSION}

The auditory map of space in the barn owl's optic tectum is shaped by auditory experience in a frequency-dependent manner (Gold and Knudsen, 1999). This shaping reflects, in part, modifications in unit tuning for both ITD and frequency (Gold and 


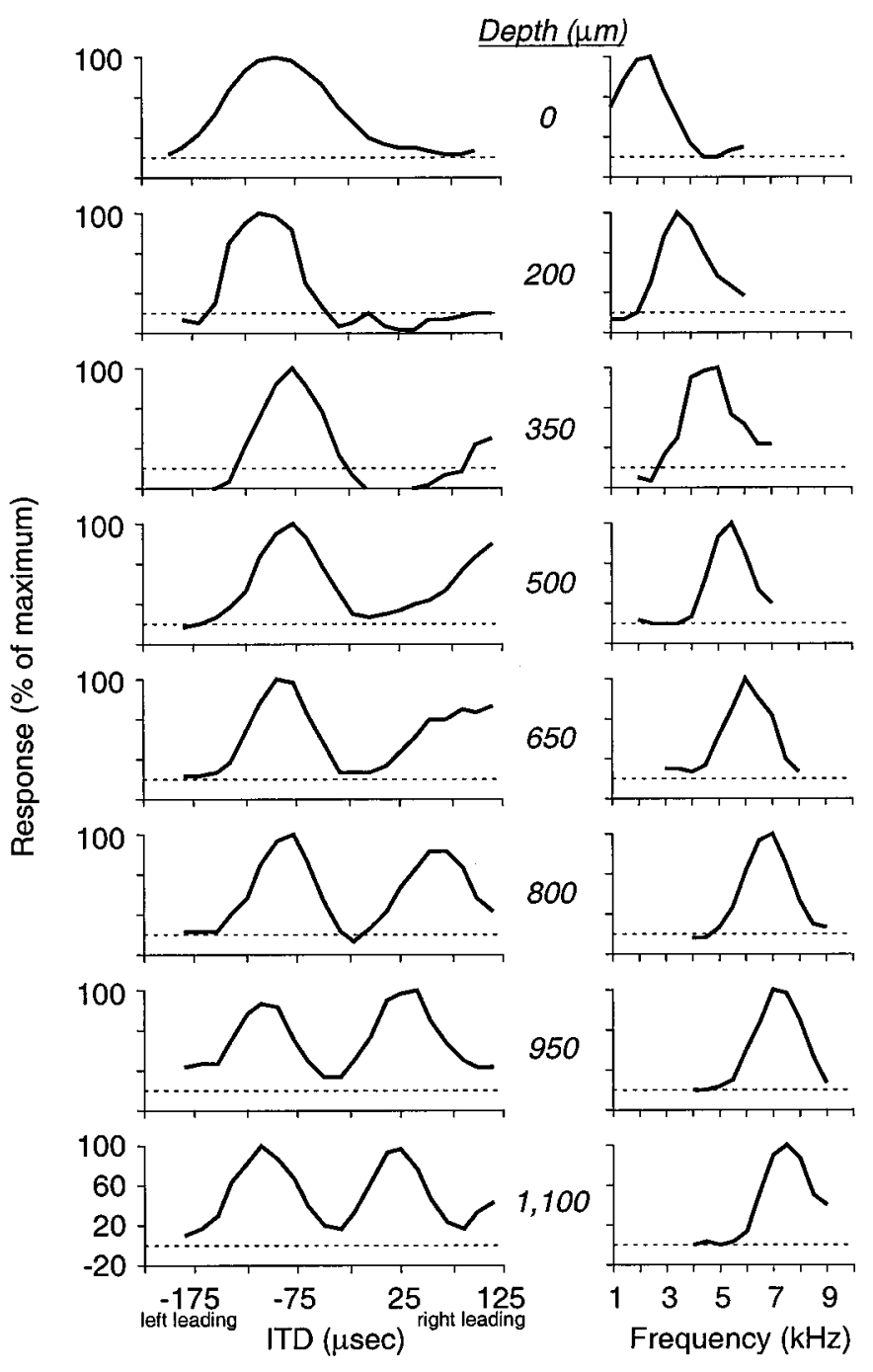

Figure 12. ITD and frequency tuning along a dorsoventral electrode penetration through the ICCls in a normal owl. Each row illustrates the broadband ITD tuning (left) and the frequency tuning (right) for a site along the penetration at the relative depth indicated in the center. Each curve is normalized to the maximum response of that curve. Note that peaks in the ITD tuning curves recur at integer multiples of the period corresponding to the best frequency of the neuron, because these neurons are tuned to interaural phase differences (Wagner et al., 1987).

Knudsen, 2000). The present results demonstrate that the experience-induced modifications observed in the tectum are caused, in large part, by plasticity that occurs at the level of the ICX, where the auditory space map is synthesized. In the following sections, we discuss the evidence for plasticity in the ICX, compare it with similar plasticity observed in owls raised with abnormal visual experience, and speculate on how this plasticity shapes tuning for ITD and frequency.

\section{Site of plasticity}

The acoustic filtering device used in this study to alter auditory experience affects sounds in a frequency-dependent manner. Adaptive modifications in the ITD tuning of neurons in the optic tecta of owls raised with the device are correspondingly frequency dependent (Gold and Knudsen, 2000). These modifications include shifts in best ITDs relative to predicted normal values of $\sim 55 \mu \mathrm{sec}$ toward open-ear leading for stimuli near 4

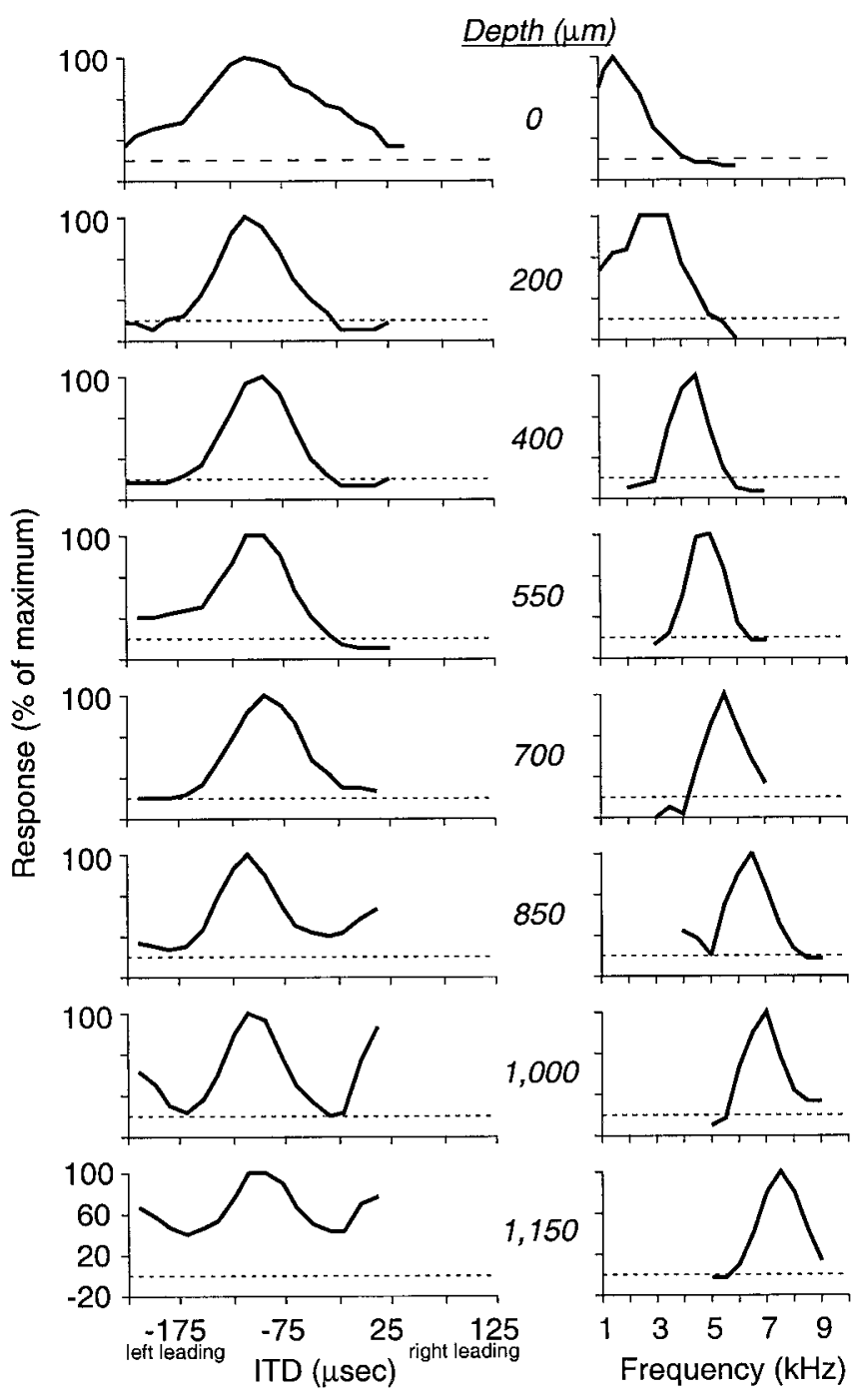

Figure 13. ITD and frequency tuning along a dorsoventral electrode penetration through the ICCls in a device-reared owl. Each row illustrates the broadband ITD tuning (left) and the frequency tuning (right) for a site along the penetration at the relative depth indicated in the center. Each curve is normalized to the maximum response of that curve. Note that peaks in the ITD tuning curves recur at integer multiples of the period corresponding to the best frequency of the neuron, because these neurons are tuned to interaural phase differences (Wagner et al., 1987).

$\mathrm{kHz}$ and $\sim 23 \mu \mathrm{sec}$ toward the opposite-ear leading for stimuli near $8 \mathrm{kHz}$ (Figs. 2, 3; Table 3). We exploited this frequency dependence in our search for a site of plasticity.

As summarized in Figure 18, the frequency-dependent changes in ITD tuning observed in the tecta of device-reared owls were evident to a large extent in the ICX, but not in the ICCls, of the same owls. In normal owls, best ITDs measured at individual sites in the ICX using 4 and $8 \mathrm{kHz}$ stimuli were roughly similar. In contrast, these best ITDs differed by $\sim 65 \mu \mathrm{sec}$ in device-reared owls, roughly matching the acoustic effects of the device. These changes were reflected in systematic shifts in the representations of frequency-specific ITDs relative to predicted normal values, including shifts in the left and right ICX of 63 and $52 \mu \mathrm{sec}$ toward open-ear leading, respectively, for stimuli near $4 \mathrm{kHz}$ and of 8 and $11 \mu \mathrm{sec}$ toward the affected-ear leading, respectively, for stimuli near 8 kHz (Figs. 5-7; Table 4). In contrast, device rearing did not 

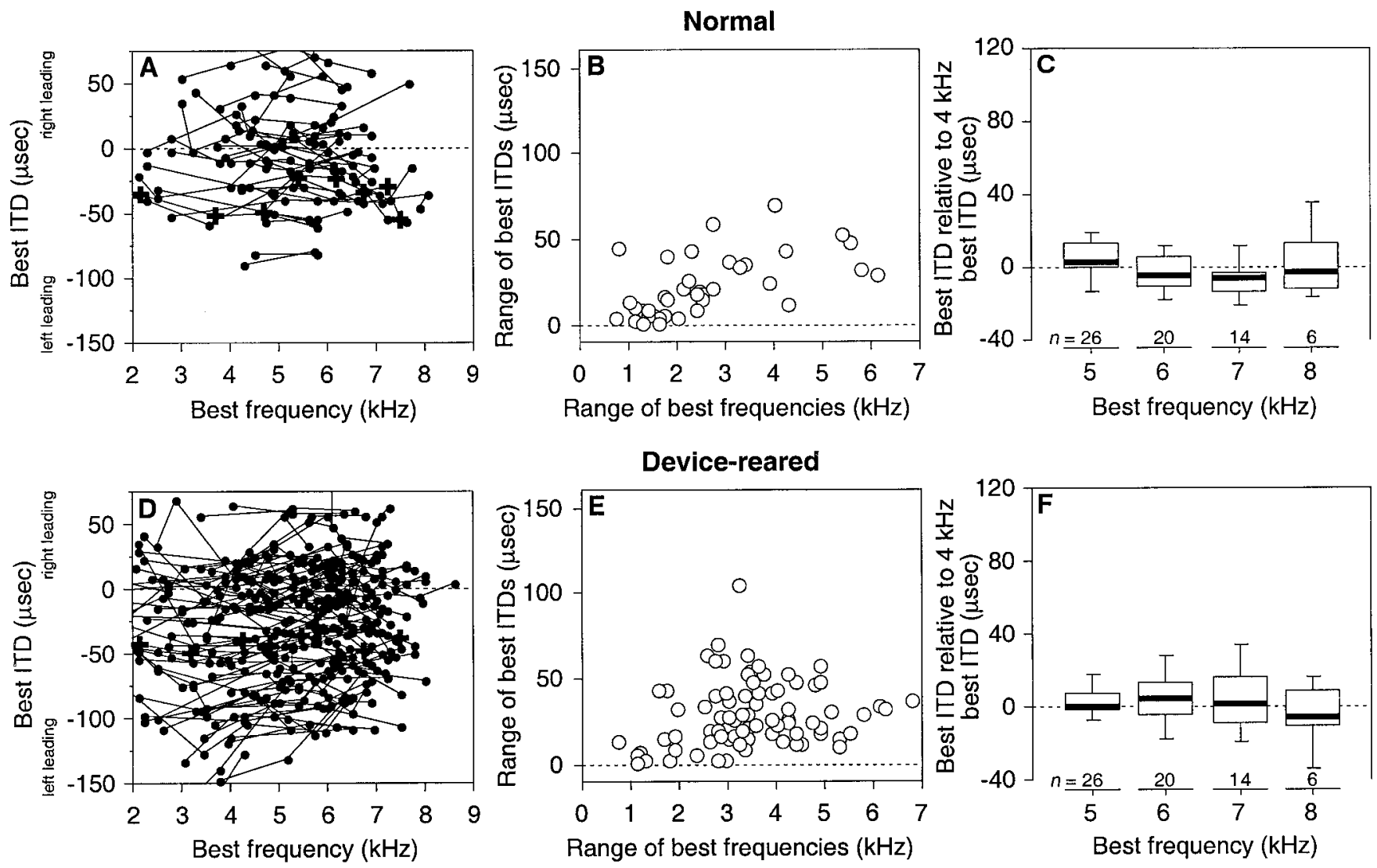

Figure 14. The frequency dependence of ITD tuning in individual dorsoventral electrode penetrations through the ICCls in normal $(A-C)$ and device-reared $(D-F)$ owls. $A$, Best ITD as a function of best frequency at individual recording sites. Each line represents data from sites in a single dorsoventral penetration. Crosses represent data from Figure 12. B, For each line shown in $A$, the range of best ITDs plotted with respect to the range of best frequencies. $C$, The difference between the mean best ITD from sites tuned to between 3 and $4.5 \mathrm{kHz}$ and the best ITD measured at a site along the same electrode penetration with the given best frequency, binned as indicated. Thick lines, boxes, and bars indicate medians, quartiles, and 10th/90th percentiles, respectively. $E-F$, Data from device-reared owls, plotted as described for $A-C$, respectively. $D$, Crosses represent data from Figure 13 . $F$, The data for each frequency did not differ significantly from the corresponding data in $C$ (Mann-Whitney $U$ test, $p>0.05$ ).

alter the representation of frequency-specific ITDs in the ICCls (Figs. 12-15; Table 5).

These changes in the tuning of ICX neurons likely arose, at least in part, from plasticity affecting signals transmitted directly along the ICCls-ICX pathway. In many cases, abnormal ITD tuning was apparent within the first $8 \mathrm{msec}$ of responses after stimulus onset. The shortest latencies of other auditory spacetuned neurons in the owl's CNS include $5 \mathrm{msec}$ in the vermis of the cerebellum; however, these responses would have to traverse at least two synapse and many millimeters of tissue along an as yet undiscovered pathway to affect ICX responses (Norris, 1982). The shortest latency of space-tuned neurons in the forebrain is 8 msec (Cohen and Knudsen, 1994, 1995). It is unlikely, therefore, that these other structures are responsible for the altered ITD tuning that is expressed in the earliest responses in the ICX.

The results also implicate the ICX as a site of plasticity for experience-dependent changes in frequency-response functions. In device-reared owls, the tonopic organization of the ICCls appeared to be normal (Fig. 16). In contrast, normally robust responses to $6 \mathrm{kHz}$ stimuli were substantially reduced in both the ICX (Figs. 8, 9) and the optic tectum (Fig. 4). Thus, frequency responses were altered at the stage where information is combined across frequencies (Knudsen, 1983b; Wagner et al., 1987).

Note that plasticity at the level of the ICX does not account for all of the changes observed in the optic tectum. For example, the frequency dependence of ITD tuning in the ICX of device-reared owls is similar to, but falls short of, that measured in the optic tectum (Fig. 18). Thus, additional plasticity in ITD tuning seems likely beyond the level of the ICX and may occur in the tectum itself. Likewise, the small shifts in ITD tuning for $4 \mathrm{kHz}$ in the ICCls of device-reared owls (Table 5) suggest additional plasticity earlier in the ITD pathway.

\section{Comparison with prism rearing}

Owls raised with prismatic spectacles experience essentially normal values of auditory localization cues, but the visual locations to which these auditory cue values correspond are displaced laterally. In contrast, owls raised with the acoustic filtering device experience frequency-dependent changes in the ranges and spatial patterns of auditory localization cues, but their vision is normal. Despite their very different effects on sensory experience, both manipulations result in shifts in the ITD tuning of tectal neurons that tend to restore alignment between the tectal maps of auditory and visual space (Knudsen and Brainard, 1991; Brainard and Knudsen, 1993; Gold and Knudsen, 1999, 2000). The present results indicate that, as in the case of prism experience, the main site of plasticity in response to device rearing is the ICX.

Prism- and device-induced changes in the representation of ITD in the ICX share a number of common features. First, both 

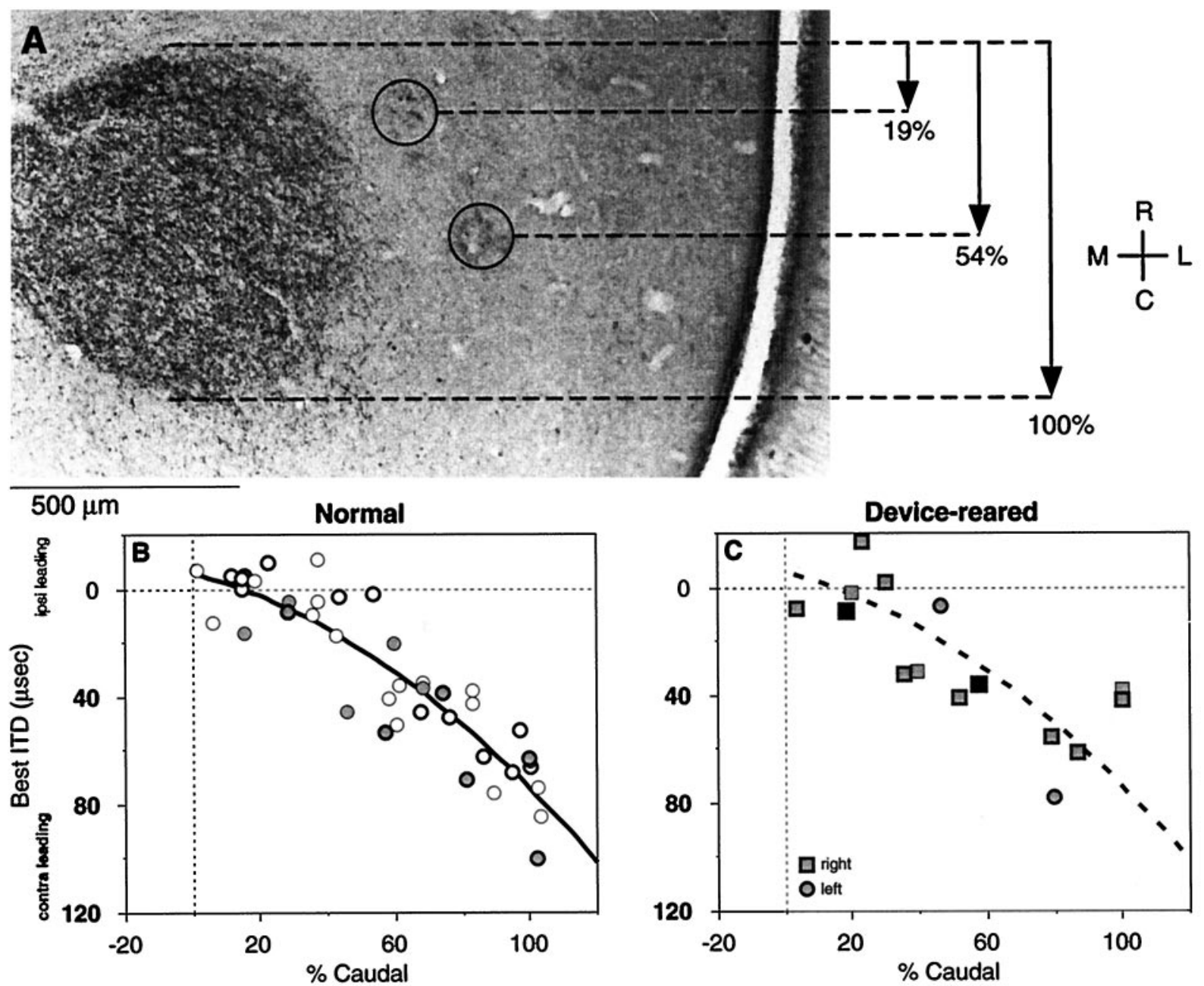

Figure 15. Representation of ITD in the ICCls of normal $(B)$ and device-reared $(A, C)$ owls. $A$, The image depicts a horizontal section through the right ICC of a device-reared owl with the core immunohistochemically stained with an antibody to calbindin. The ICC core (darkly stained circular region) served as an anatomical reference for quantifying the locations of recording sites in the ICCls. The locations of lesions (circled) were quantified as percentages of the distance from the rostral to the caudal end of the core. $B$, Best ITD measured in the $6 \mathrm{kHz}$ lamina of normal owls as a function of rostrocaudal position of the recording site relative to the ICC core borders. Recording site locations were determined either by lesion reconstruction (bold symbols) or by estimation based on microdrive coordinates relative to recovered lesions. Data from the left and right side of the brain are included. Plain and bold labels represent ipsilateral- and contralateral-ear-leading values, respectively. Open symbols represent previously published data (Brainard and Knudsen, 1993). The solid line is a second-order polynomial fit to the data $\left(r^{2}=0.83\right.$; ANOVA, $\left.p<0.001\right)$. $C$, Representation of ITD in the ICCls of device-reared owls, plotted in the same format as in $B$. Data from the right and left side of the brain are depicted as squares and circles, respectively. Solid symbols indicate best ITDs measured at the two sites depicted in $A$. The dashed line is the fit to the normal data derived in $B$.

Table 5. Frequency-specific ITD tuning in the ICCIs

Best ITD relative to predicted normal ${ }^{a}$

\begin{tabular}{|c|c|c|c|c|c|c|c|c|c|}
\hline \multirow[b]{2}{*}{ Experience } & \multicolumn{3}{|l|}{$4 \mathrm{kHz}$} & \multicolumn{3}{|l|}{$6 \mathrm{kHz}$} & \multicolumn{3}{|l|}{$8 \mathrm{kHz}$} \\
\hline & Median & $\mathrm{IQR}^{b}$ & $n$ & Median & $\mathrm{IQR}^{b}$ & $n$ & Median & $\mathrm{IQR}^{b}$ & $n$ \\
\hline Normal & 5 & 16 & 50 & 0 & 7 & 74 & -9 & 14 & 10 \\
\hline Device-reared & $-5^{*}$ & 22 & 114 & 0 & 8 & 191 & -5 & 21 & 45 \\
\hline
\end{tabular}

${ }^{a}$ See text for explanation of predicted normal. ITD was measured at sites with best frequencies between 3 and $5 \mathrm{kHz}$ (" 4 $\mathrm{kHz}$ "), between 5 and $7 \mathrm{kHz}$ ("6 kHz"), and between 7 and $9 \mathrm{kHz}$ ("8 kHz").

${ }^{b} \mathrm{IQR}$, Interquartile range.

*Significantly different from normal (Mann-Whitney $U$ test, $p<0.01$ ).

can account for a large part of the changes in ITD tuning observed in the tectum. Second, both types of change have a similar spatial pattern within the ICX, with small or no changes in the portion of the nucleus near the ICCls-ICX border, and larger changes at more lateral locations (Brainard and Knudsen, 1993). Third, both types of change can be observed in the earliest responses of neurons in the ICX, implying that the plasticity affects signals coming directly from the ICCls. These common 


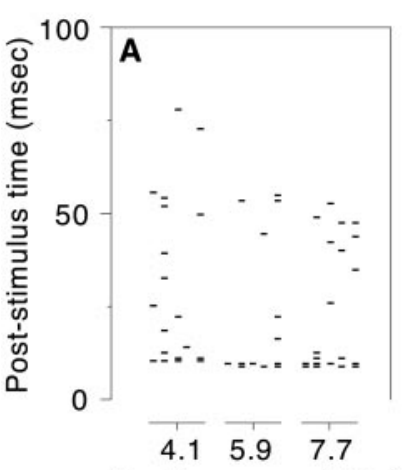

Best frequency $(\mathrm{kHz})$

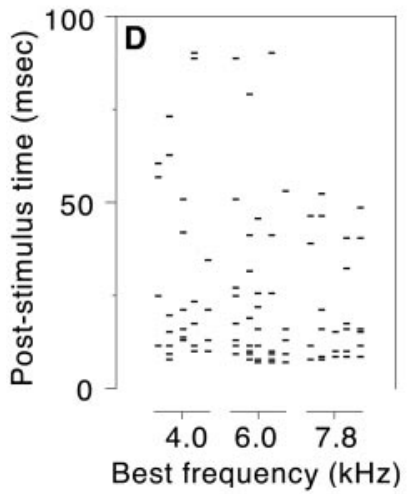

Normal

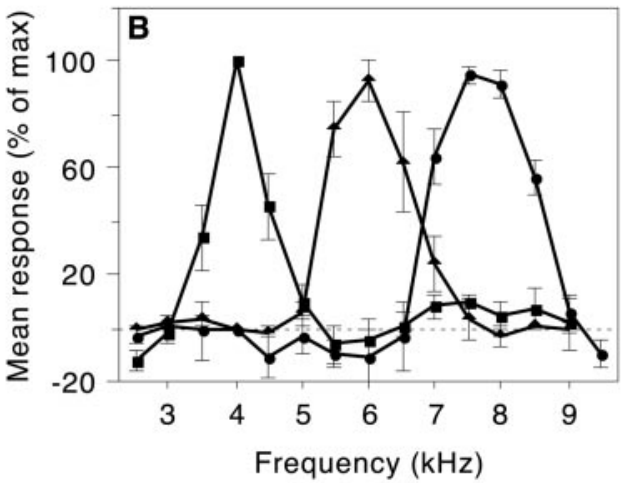

Device-reared

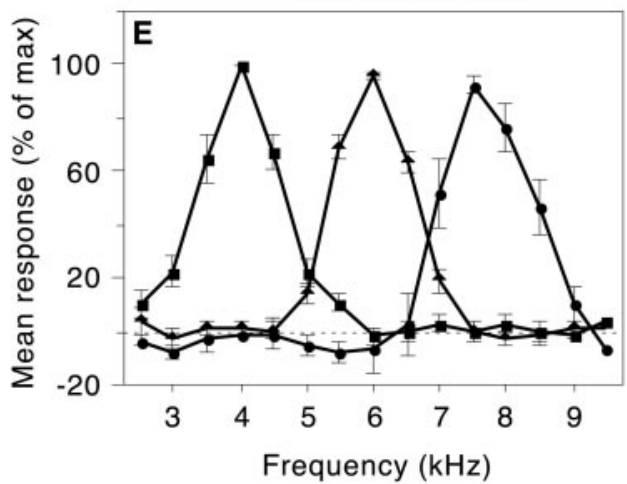

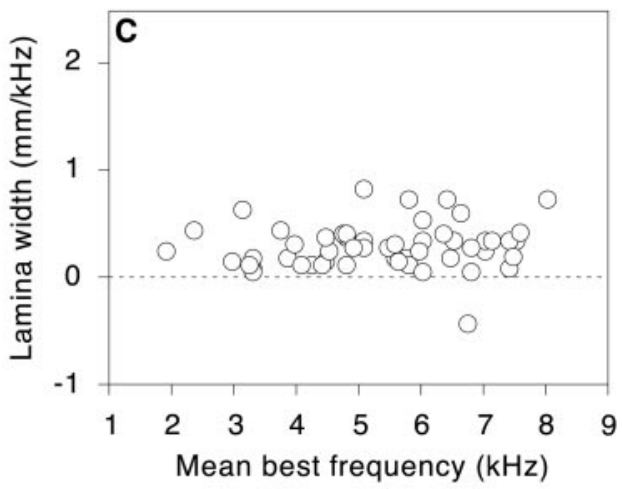

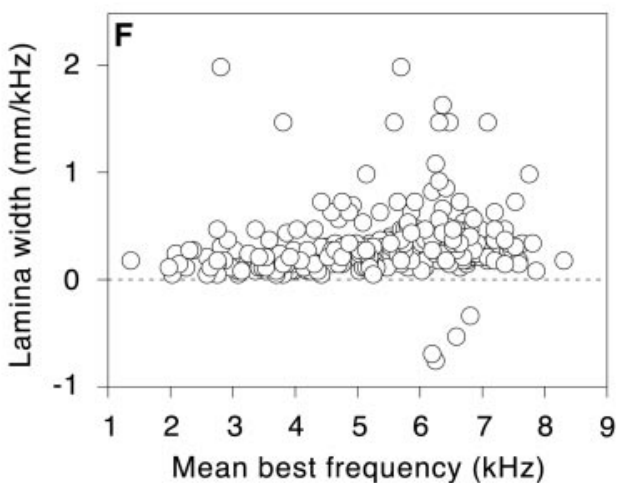

Figure 16. Frequency responses in the ICCls of normal $(A-C)$ and device-reared $(D-\mathrm{F})$ owls. $A$, Raster display representing trial-by-trial responses to a tonal stimulus of the frequency indicated during the $100 \mathrm{msec}$ after stimulus onset. Responses were measured at three different sites along a single electrode penetration; the stimulus frequency was chosen to match the best frequency of the given site. Five repetitions per stimulus are shown. $B$, Composite frequency-response functions, depicting the means and SDs of normalized frequency-response functions from various sites in the ICCls of four normal owls. The three curves are composites of frequency-response functions with best values between 3.8 and $4.2 \mathrm{kHz}$ (squares: data from 6 sites, width $=0.8 \mathrm{kHz}$ ), between 5.8 and $6.2 \mathrm{kHz}$ (triangles: $n=4$, width $=1.4 \mathrm{kHz}$ ), and between $7.6 \mathrm{and} 8.0 \mathrm{kHz}($ circles: $n=6$, width $=1.7 \mathrm{kHz})$. $C$, Lamina width in the ICCls of normal owls. For all adjacent pairs of recording sites in a given dorsoventral electrode penetration through the ICCls, the amount of tissue per kilohertz change in best frequency between the two sites (computed as the change in depth, moving ventrally, divided by the change in best frequency) is plotted as a function of the average of the best frequencies measured at the two sites. Positive ordinate values indicate a change toward higher best frequencies ventrally. Larger absolute ordinate values indicate wider frequency laminae. $D-F$, Data from device-reared owls plotted in the same format as in $A-F$, respectively. $E$, Squares: $n=17$, width $=1.4 \mathrm{kHz}$; triangles: $n=39$, width $=1.4 \mathrm{kHz}$; circles: $n=8$, width $=1.6 \mathrm{kHz}$.
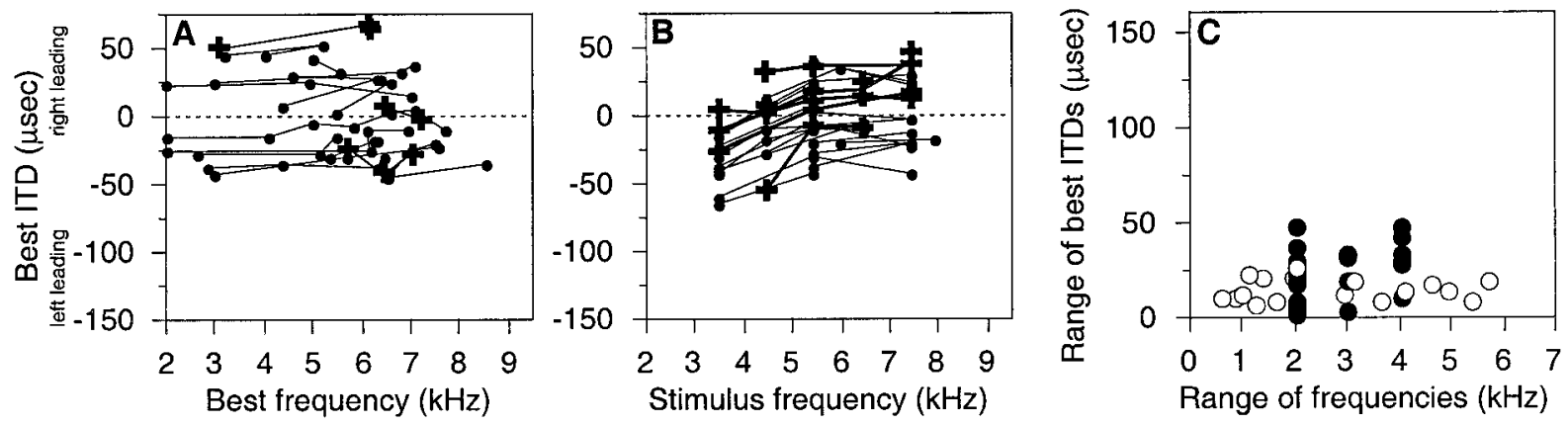

Figure 17. Frequency-specific ITD tuning near the ICCls-ICX border in device-reared owls. $A$, Data from penetrations that had a systematic progression of narrowly tuned best frequencies. Best ITD is plotted as a function of best frequency measured at a given site. Each line represents data from a single penetration. Triangles represent data from sites whose locations at the ICCls-ICX border were confirmed via either lesion reconstruction or estimation based on microdrive coordinates relative to recovered lesions. $B$, Data from sites that responded to a broad range of frequencies. Best ITD for narrowband $(1 \mathrm{kHz}$ bandwidth) stimuli is plotted as a function of the center frequency of the stimulus. Each line represents data from a single recording site. Triangles are as in $A$. $C$, For each line shown in $A$ and $B$, the range of best ITDs plotted with respect to the range of either the best frequencies measured (for each line shown in $A$; open symbols) or the stimulus center frequencies tested (for each line shown in $B$; closed symbols). 


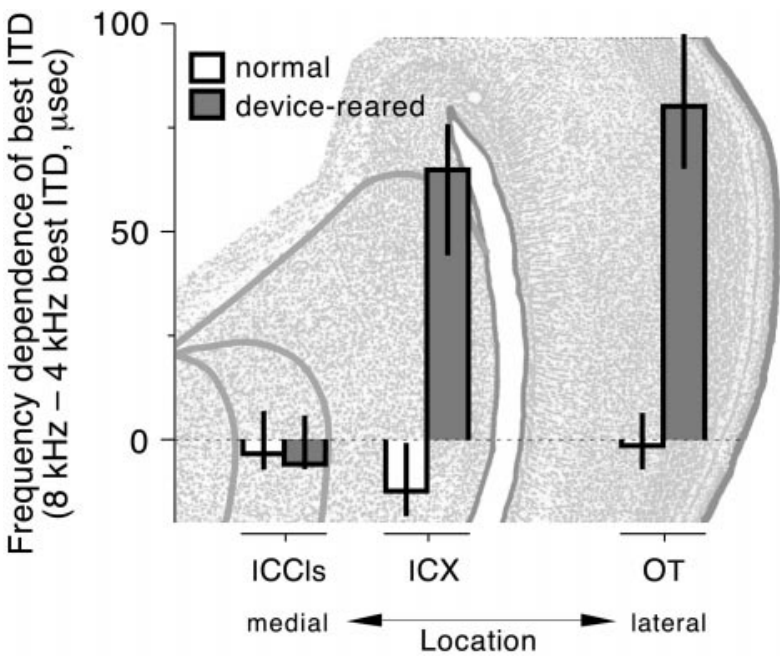

Figure 18. Summary of frequency-dependent shifts in ITD tuning in the inferior colliculus and optic tectum of device-reared owls. Bars and lines indicate the median values and interquartile ranges, respectively, of the difference between the best ITD at $8 \mathrm{kHz}$ and the best ITD at $4 \mathrm{kHz}$. Data for the ICCls (see Fig. 14C,F) are from individual penetrations. Data for the ICX (see Fig. $6 C, F$ ) and the optic tectum $(O T)$ (see Fig. $2 B, D)$ are from individual sites. Normal owls: ICCls versus ICX, $p=0.16$ (Mann-Whitney $U$ test); ICX versus optic tectum, $p=0.04$. Devicereared owls: ICCls versus ICX, $p<0.0001$; ICX versus optic tectum, $p=0.01$.

features suggest that both visual and auditory experience may drive a common mechanism of plasticity at the level of the ICX.

\section{Plasticity of ICC-ICX connections}

The pattern of connectivity from the ICCls to the ICX plays an important role in establishing the binaural tuning of ICX neurons. For example, a given ICX neuron normally receives input from an array of ICCls neurons that represents a single ITD across a range of frequencies. This convergent projection is thought to confer on ICX neurons tuning to unique ITD values (Knudsen, 1983b; Takahashi and Konishi, 1986; Wagner et al., 1987). The experience-induced plasticity in ITD and frequency tuning that we observed at the level of the ICX appears to involve changes both in the pattern of this anatomical projection and in the strength of existing connections.

In prism-reared owls, modification of ITD tuning in the ICX is correlated with an anatomical reorganization of the afferent projection from the ICCls (Feldman and Knudsen, 1997). These anatomical changes seem to provide a given ICX neuron with novel input from an additional array of ICCls neurons that represents the newly learned ITD value. This anatomical reorganization is thought to be responsible for the prism-induced changes in ITD tuning in the ICX.

In principle, an anatomical reorganization of the ICCls-ICX projection could also account for the device-induced changes in ITD tuning. However, a systematic shift in the projection, as occurs in prism-reared owls, could not account for the frequency dependence of these changes. Instead, device-induced changes would require the establishment of novel ICCls-ICX projections that vary in direction and magnitude depending on the frequency lamina of origin. This would imply that the ICCls-ICX connection is not restricted to a simple pattern of projections from dorsoventral arrays of ICCls neurons but instead is highly modifiable, with the capacity to be shaped into complex patterns as determined by the experience of the individual.
The results suggest that the strength of existing, excitatory ICCls-ICX connections can also be modified by experience. A dramatic effect of device experience was the weakening of normally strong ICX responses to stimulus frequencies near $6 \mathrm{kHz}$. This weakening may have resulted from a device-induced deprivation of excitatory input from ICCls neurons tuned to frequencies near $6 \mathrm{kHz}$ relative to input from other frequencies. Insertion of the device in normal owls substantially reduces responses in the tectum to $6 \mathrm{kHz}$ signals relative to other frequencies (Gold and Knudsen, 1999), implying that at $6 \mathrm{kHz}$, the severe acoustic effects of the device cause relatively few locations to give rise to combinations of ITD and ILD values that are within the normal range. As a result, the activity of neurons in the ICCls that were tuned to $6 \mathrm{kHz}$ and to normal ITD/ILD combinations rarely contributed to postsynaptic discharges in the ICX, particularly in comparison with the contributions of other frequency laminae. This competitive disadvantage could have resulted in a weakening of connections in the ICX from neurons in the $6 \mathrm{kHz}$ lamina of the ICCls. Such a mechanism could be responsible not only for the device-induced loss of responses to stimuli near $6 \mathrm{kHz}$, but also for the normal topographic variation in frequency tuning across the tectal space map that matches the filtering properties of the external ears (Knudsen, 1984a; Keller et al., 1998).

Experience-dependent regulation of the pattern of ICC-ICX connectivity may thus be responsible for providing the ICX with a fundamentally different functional organization from that in the ICC. Neurons in the ICC appear to be organized with respect to their tuning to particular values of localization cues and frequency, regardless of how those values correspond with spatial locations. In contrast, neurons in the ICX appear to integrate information to achieve spatial tuning that is appropriate for the individual, regardless of the values of the localization cues or the frequencies of sound to which the neurons must respond to achieve that spatial tuning.

\section{REFERENCES}

Brainard MS, Knudsen EI (1993) Experience-dependent plasticity in the inferior colliculus: a site for visual calibration of the neural representation of auditory space in the barn owl. J Neurosci 13:4589-4608.

Carr CE, Konishi M (1988) Axonal delay lines for time measurement in the owl's brainstem. Proc Natl Acad Sci USA 85:8311-8315.

Carr CE, Konishi M (1990) A circuit for detection of interaural time differences in the brain stem of the barn owl. J Neurosci 10:3227-3246.

Cohen YE, Knudsen EI (1994) Auditory tuning for spatial cues in the barn owl basal ganglia. J Neurophysiol 72:285-298.

Cohen YE, Knudsen EI (1995) Binaural tuning of auditory units in the forebrain archistriatal gaze fields of the barn owl: local organization but no space map. J Neurosci 15:5152-5168.

Feldman DE, Knudsen EI (1997) An anatomical basis for visual calibration of the auditory space map in the barn owl's midbrain. J Neurosci 17:6820-6837.

Gold JI, Knudsen EI (1999) Hearing impairment induces frequencyspecific adjustments in auditory spatial tuning in the optic tectum of young owls. J Neurophysiol 82:2197-2209.

Gold JI, Knudsen EI (2000) Abnormal auditory experience induces frequency-specific adjustments in unit tuning for binaural localization cues in the optic tectum of juvenile owls. J Neurosci 20:862-877.

Gordon B (1973) Receptive fields in deep layers of cat superior colliculus. J Neurophysiol 36:157-178.

Harris LR, Blakemore C, Donaghy M (1980) Integration of visual and auditory space in the mammalian superior colliculus. Nature 288:56-59.

Keller CH, Hartung K, Takahashi TT (1998) Head-related transfer functions of the barn owl: measurement and neural responses. Hearing Res 118:13-34.

King AJ, Palmer AR (1983) Cells responsive to free-field auditory stimuli in guinea-pig superior colliculus: distribution and response properties. J Physiol (Lond) 342:361-381. 
King AJ, Hutchings ME, Moore DR, Blakemore C (1988) Developmental plasticity in the visual and auditory representations in the mammalian superior colliculus. Nature 332:73-76.

King AJ, Moore DR, Hutchings ME (1994) Topographic representation of auditory space in the superior colliculus of adult ferrets after monaural deafening in infancy. J Neurophysiol 71:182-194.

Knudsen EI (1982) Auditory and visual maps of space in the optic tectum of the owl. J Neurosci 2:1177-1194.

Knudsen EI (1983a) Early auditory experience aligns the auditory map of space in the optic tectum of the barn owl. Science 222:939-942.

Knudsen EI (1983b) Subdivisions of the inferior colliculus in the barn owl (Tyto alba). J Comp Neurol 218:174-186.

Knudsen EI (1984a) Auditory properties of space-tuned units in owl's optic tectum. J Neurophysiol 52:709-723.

Knudsen EI (1984b) Synthesis of a neural map of auditory space in the owl. In: Dynamic aspects of neocortical function (Edelman GM, Cowan WM, Gall WE, eds), pp 375-396. New York: Wiley.

Knudsen EI (1985) Experience alters the spatial tuning of auditory units in the optic tectum during a sensitive period in the barn owl. J Neurosci 5:3094-3109.

Knudsen EI, Brainard MS (1991) Visual instruction of the neural map of auditory space in the developing optic tectum. Science 253:85-87.

Knudsen EI, Knudsen PF (1983) Space-mapped auditory projections from the inferior colliculus to the optic tectum in the barn owl (Tyto alba). J Comp Neurol 218:187-196.

Knudsen EI, Konishi M (1978) Space and frequency are represented separately in auditory midbrain of the owl. J Neurophysiol 41:870-884.

Knudsen EI, Esterly SD, du Lac S (1991) Stretched and upside-down maps of auditory space in the optic tectum of blind-reared owls; acoustic basis and behavioral correlates. J Neurosci 11:1727-1747.

Middlebrooks JC, Knudsen EI (1984) A neural code for auditory space in the cat's superior colliculus. J Neurosci 4:2621-2634.

Mogdans J, Knudsen EI (1992) Adaptive adjustment of unit tuning to sound localization cues in response to monaural occlusion in developing owl optic tectum. J Neurosci 12:3473-3484.
Mogdans J, Knudsen EI (1993) Early monaural occlusion alters the neural map of interaural level differences in the inferior colliculus of the barn owl. Brain Res 619:29-38.

Mogdans J, Knudsen EI (1994) Site of auditory plasticity in the brain stem (VLVp) of the owl revealed by early monaural occlusion. J Neurophysiol 72:2875-2891.

Moiseff A, Konishi M (1981a) Neuronal and behavioral sensitivity to binaural time differences in the owl. J Neurosci 1:40-48.

Moiseff A, Konishi M (1981b) The owl's interaural pathway is not involved in sound localization. J Comp Physiol 144:299-304.

Norris JC (1982) Sensitivity to sound location and other response properties of auditory neurons in the cerebellum of the owl. $\mathrm{PhD}$ thesis, Stanford University.

Olsen JF, Knudsen EI, Esterly SD (1989) Neural maps of interaural time and intensity differences in the optic tectum of the barn owl. J Neurosci 9:2591-2605.

Sullivan WE, Konishi M (1986) Neural map of interaural phase difference in the owl's brainstem. Proc Natl Acad Sci USA 83:8400-8404.

Takahashi T, Konishi M (1986) Selectivity for interaural time difference in the owl's midbrain. J Neurosci 6:3413-3422.

Takahashi T, Konishi M (1988) Projections of the cochlear nuclei and nucleus laminaris to the inferior colliculus of the barn owl. J Comp Neurol 274:190-211.

Takahashi T, Carr CE, Brecha N, Konishi M (1987) Calcium binding protein-like immunoreactivity labels the terminal field of nucleus laminaris of the barn owl. J Neurosci 7:1843-1856.

Takahashi T, Wagner H, Konishi M (1989) Role of commissural projections in the representation of bilateral auditory space in the barn owl's inferior colliculus. J Comp Neurol 281:545-554.

Updyke BV (1974) Characteristics of unit responses in superior colliculus of the Cebus monkey. J Neurophysiol 37:896-909.

Wagner H, Takahashi T, Konishi M (1987) Representation of interaural time difference in the central nucleus of the barn owl's inferior colliculus. J Neurosci 7:3105-3116. 